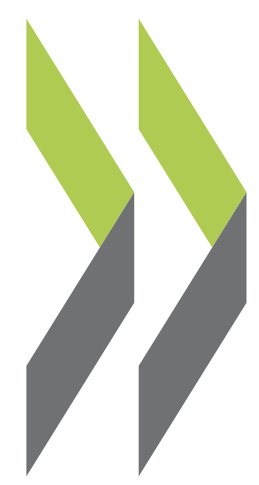

OECD Science, Technology and Industry Working Papers $2003 / 05$

\title{
Biotechnology Indicators and Public Policy
}

\section{Anthony Arundel}


Organisation de Coopération et de Développement Economiques

Organisation for Economic Co-operation and Development

25-Jun-2003

DIRECTORATE FOR SCIENCE, TECHNOLOGY AND INDUSTRY

English - Or. English

BIOTECHNOLOGY INDICATORS AND PUBLIC POLICY

(STI WORKING PAPERS 2003/5)

Statistical Analysis of Science, Technology and Industry

Anthony Arundel 


\section{STI Working Paper Series}

The Working Paper series of the OECD Directorate for Science, Technology and Industry is designed to make available to a wider readership selected studies prepared by staff in the Directorate or by outside consultants working on OECD projects. The papers included in the series cover a broad range of issues, of both a technical and policy-analytical nature, in the areas of work of the DSTI. The Working Papers are generally available only in their original language - English or French - with a summary in the other.

Comments on the papers are invited, and should be sent to the Directorate for Science, Technology and Industry, OECD, 2 rue André-Pascal, 75775 Paris Cedex 16, France.

The opinions expressed in these papers are the sole responsibility of the author(s) and do not necessarily reflect those of the OECD or of the governments of its member countries.

\section{http://www.oecd.org/sti/working-papers}




\title{
BIOTECHNOLOGY INDICATORS AND PUBLIC POLICY
}

\author{
Antony Arundel \\ MERIT, Maastricht, the Netherlands
}

\begin{abstract}
This working paper provides input and a framework for a broader discussion of the identification of user needs that should inform the development of biotechnology statistics and indicators. This document identifies and evaluates the main types of indicators that may be required to inform policy actions. Given the embryonic state of biotechnology, the main focus for policy is on S\&T policies where four main types of S\&T policies - supporting biotechnology research, diffusing biotechnology knowledge and expertise, commercialising biotechnology research and encouraging the adoption (application and use) of biotechnology - are used as a framework for developing relevant statistics. In addition to more generic S\&T polices, the paper explores the development of indicators by major application area -agriculture, health, industrial processing and environmental applications. The paper includes both an evaluation of how existing indicators can be used, and the types of new indicators that can be obtained from existing data sources or which need to be created, such as through new surveys.
\end{abstract}


TABLE OF CONTENTS

\begin{tabular}{|c|c|}
\hline 1. & Introduction .. \\
\hline 2. & The policy indicator nexus ................. \\
\hline 2.1 & The definition of biotechnology.... \\
\hline 2.2 & Policy goals for biotechnology .................................. \\
\hline 2.3 & 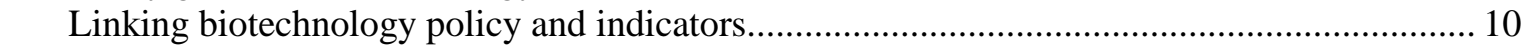 \\
\hline 2.4 & Indicators and S\&T policy \\
\hline 3. & 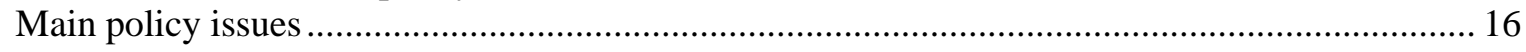 \\
\hline 3.1 & 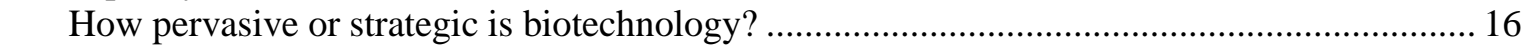 \\
\hline 3.2 & Dissemination of knowledge \\
\hline 3.3 & Human resources. 19 \\
\hline 3.4 & Social acceptance of biotechnology ……................... \\
\hline 4. & 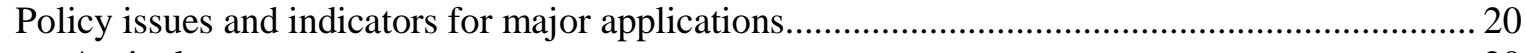 \\
\hline 4.1 & 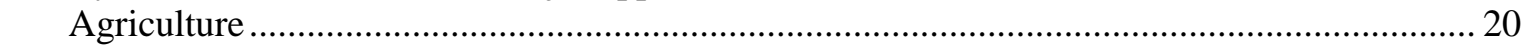 \\
\hline 4.2 & Biotechnology and health \\
\hline 4.3 & Industrial processing and environmental applications \\
\hline 5. & 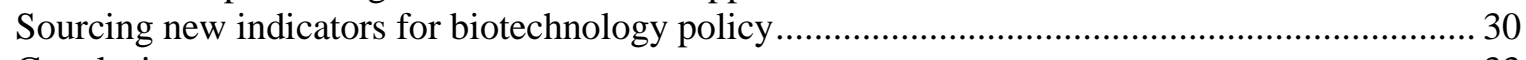 \\
\hline 6. & 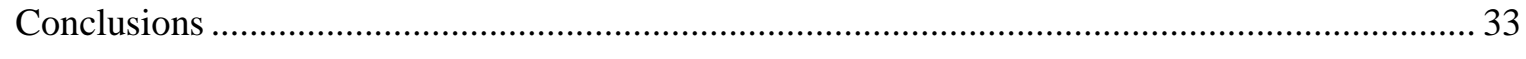 \\
\hline
\end{tabular}


DSTI/DOC(2003)5

\section{BIOTECHNOLOGY INDICATORS AND PUBLIC POLICY}

\section{Introduction}

A commonly accepted view among many academics and policy makers in OECD countries is that the wave of innovation and investment based on information and communication technologies (ICT) will be followed by biotechnology. This would have wide-ranging social and policy implications, since biotechnology is thought to offer enormous opportunities "for improving the quality of life through the creation of highly skilled jobs, improved competitiveness and economic growth" and to provide "new tools to address different challenges such as protection of the environment" (European Commission, 2001). This enthusiasm for biotechnology can, in part, be traced back to a 1988 article by Freeman and Perez, which suggested that biotechnology would emerge from the current Kondratieff long wave of economic growth based on ICT. This would make biotechnology the sixth long wave since the industrial revolution in the 1770s.

An essential feature of all innovations that have driven long waves of economic growth is that they are pervasive, in the sense that they have applications and uses in many different sectors of an economy. Biotechnology appears to meet this requirement, with applications in human and animal health, industrial processing, and in almost all resource based sectors, such as agriculture, forestry, aquaculture, and mining (PEW, 2001). Policy documents consistently point out that these pervasive or generic characteristics of biotechnology mean that it is of strategic importance to knowledge-based economies. The implication of assigning a "strategic" status to this technology means that nations that fail to develop biotechnology capabilities will lag behind others in terms of productivity, which will lead to lower relative per capita incomes; outcomes that governments would wish to avoid.

There is, however, a danger in uncritically accepting the assigned role of biotechnology. Even if modern economies did evolve through long waves of radical innovations that create new investment opportunities - and this perspective is not accepted by many economists - we cannot assume that biotechnology will form the next wave. The history of innovation offers many examples of technologies that failed to live up to their initial expectations. If Freeman and Perez had been writing in the mid-1960s, they may have given a much brighter future to nuclear power with its promise of "electricity too cheap to meter". Instead, we have had electrical power crises in California but long distance telephone rates that are almost free in comparison to the rates charged four decades ago.

An evaluation of the structure of modern economies will also show that biotechnology, while pervasive, is unlikely to ever play the same economic role as ICT. A recent study by the European Commission (EC, 2001) estimates that biotechnology has potential applications in economic sectors that accounted for EUR 450 billion of gross value-added and for 9 million jobs in the European Union in the mid-1990s. While impressive, this does not mean that all jobs and value-added in these sectors would be based, in some way, on biotechnology. ${ }^{1}$ Furthermore, these maximum estimates are equivalent to about $9 \%$ of total

1. Similarly, the estimate by Burke and Thomas (1997) of 3.65 million biotechnology jobs in the EU in 2005 assumes that all employment in the food processing and agriculture sectors will be dependent, in some way, on biotechnology. This is highly unlikely in food processing. Nor is it necessarily safe to assume that 
value added and $8 \%$ of total employment, which are only small fractions of total value added and employment. This should be no surprise. For example, even if we assume that all pharmaceutical employment is "biotechnology-dependent", this would account for less than $0.4 \%$ of total employment in the European Union in $1999^{2}$. In fact, biotechnology will account for far fewer jobs in the pharmaceutical sector since only $16 \%$ of new drugs introduced onto the world market since 1997 (Ashton, 2001) were bio-pharmaceuticals.

Based on current research trajectories, the potential application of biotechnology is limited to some manufacturing sectors ${ }^{3}$ and to the resource sectors, even assuming that the price of biotechnology is competitive with alternative technologies. This places an upper limit on the potential economic impacts of this technology, with services accounting for about $70 \%$ of employment in most advanced economies. In comparison, there is hardly a single field of economic activity in modern economies that do not use, apply, or develop ICT. In fact, there are probably very few jobs that do not use ICT in some way, even if the employees themselves do not recognize their dependence on this family of technologies ${ }^{4}$. Barring a major, unseen expansion of the applications of biotechnology, ${ }^{5}$ biotechnology is unlikely to ever approach the pervasiveness of ICT.

Some of these limitations in the application of biotechnology may be starting to show up in the basic indicators that are used to track this technology. Ernst \& Young has been compiling data on dedicated biotechnology firms (DBFs) in the United States and Europe through most of the 1990s. Between 1998 and 2001, total DBF employment in Europe increased by $94 \%$ compared to $25 \%$ in the United States, while the number of DBFs increased by $81 \%$ in Europe between 1997 and 2001 compared to a 14\% increase in the United States. The higher rate of employment growth in Europe is partly due to Europe starting from a much lower base of 45000 employees in 1998, compared to 153000 in the US. It appears that the growth of DBFs in the United States is starting to level off, while the more rapid growth in Europe could be due to catching-up combined with large public subsidies, as in Germany. ${ }^{6}$ Furthermore, even though Ernst and

all agricultural activity will be based on modern biotechnology. Even though Buttel (2000) assumes that genetic engineering is now the dominant method for developing new seed varieties, a recent survey of European seed firms estimates that only $10 \%$ to $38 \%$ of seed development budgets are spent on genetic engineering (Arundel, 2001). No comparable data are available for the United States, but genetic engineering is unlikely to be the main developmental method for most crops, since the use of this technology has been concentrated on a limited number of seed crops with very large markets. As an example, three crops (maize, potatoes, and soybeans) accounted for $64 \%$ of all US field trials of genetically modified (GM) crops up until January 2002, while maize, sugar beet, and rapeseed accounted for $67 \%$ of all EU field trials up until April 2001.

2. EFPIA (2001) estimates 536215 employees in the EU in the pharmaceutical sector in 1999, compared to total employment in all sectors of approximately 154 million.

3. In 1997, the main manufacturing sectors with biotechnology applications included pharmaceuticals, petroleum refining, chemicals, food and beverages, and wood, pulp and paper (Arundel and Rose, 1999). Other sectors with possible applications include textiles and instruments (bio-sensors).

4. As an example, a cashier ringing up sales is using an advanced piece of IT equipment that both manages the sale and feeds data to inventory control systems.

5. One possibility is the replacement of silicon-based chips with organic biological chips. There are a few applications of biotechnology to service sectors, such as in waste treatment. Biotechnology firms also appear in research services (ISIC 73), but these are usually firms that either have no product sales so far, and are therefore not classified in an industrial sector, or which provide platform services to industrial or resource-based firms.

6. Many German DBFs are too small to be viable and have very few drugs under development (Mitchell, 2002). 
Young predicted in 1998 that the American DBF sector would move into net profitability by 2000, this had not happened, with the net loss increasing from USD 5.1 billion in 1998 to USD 5.8 billion in 2000 and increasing again to USD 6.9 billion in 2001 (Ernst and Young, 2001; 2002). ${ }^{7}$

This broad outline on the possibilities and limitations of biotechnology leads directly to two major challenges for the use of indicators to inform public policy on biotechnology. First, we need reliable indicators for tracking the economic development of biotechnology. Part of the over-optimistic evaluations of biotechnology in many policy documents is due to a dependence on measures of R\&D spending and innovative outputs such as patents. These provide useful information to biotechnology firms, venture capitalists and governments on the rapid growth of biotechnology research, but there is no assured link between investment in research and innovation - research projects may fail.

Indicators for the creation of biotechnology need to be complemented by adequate indicators for the economic effects of biotechnology. In particular, we need more indicators for the application of biotechnology (Arundel, 2000). As a pervasive technology - although with a much more limited range of applications than ICT - biotechnology should start to be applied by many firms that do not perform biotechnology R\&D. ${ }^{8}$ The declining growth rate for DBFs is part of the same process, with increasing consolidation and the adoption of biotechnology by large firms active in other technologies. We need indicators that can identify the use of biotechnology by large, diversified firms. And, since biotechnology is largely a process innovation, we could use indicators for productivity improvements as a result of its application. ${ }^{9}$

Second, and more importantly, the economic impacts of biotechnology are likely to be substantially less than its impacts on environmental conditions and on the quality of life. By stressing indicators for investment in innovation and economic outcomes such as the share of "biotechnology dependent jobs", we run the danger of missing the main story. As noted above, the employment and value-added impacts of medical and health biotechnology are unlikely to account for more than a small share of total economic activity. But, these applications could make substantial improvements to the quality of life, or what can be viewed as "social" productivity. "White" biotechnology (the application of biotechnology to industrial processing) could also have significant benefits through reducing pollution, waste, and material and energy inputs (EuropaBio, 2001; IPTS/ESTO, 2001). We need indicators that can identify these and other benefits.

To sum up, the relevant policy issues for biotechnology today require more than indicators for biotechnology research, since the main impacts of biotechnology will involve social benefits and productivity improvements. Many of the relevant policy issues concern the public interest - or how to ensure that biotechnology can meet its promise to improve the quality of life in both developed and developing countries.

7. Although employment in American DBFs increased from an estimated 153000 in 1998 to 191000 in 2001, the loss per employee has not changed appreciably between 1998, 1999, 2000, and 2001. In 2000, only 60 (17.7\%) of the 339 publicly-traded DBFs reported a profit (Ernst and Young, 2001).

8. The high R\&D intensity of many biotechnology firms is, ironically, a sign of low economic impacts. Much of the economic output is the research, as with new pharmaceuticals. In these sectors, the research cannot be leveraged into substantial sales, as in many low technology sectors such as food and beverages or wood products, or in the computer and telecom equipment sectors.

9. Productivity improvements are likely to produce employment losses, although these could occur in different sectors. One example is crop seed varieties that are genetically modified (GM) to resist common pests such as certain fungi, nematodes, and insects. The adoption of pest resistant GM seed by farmers could reduce employment by firms that develop chemical pesticides (Tait et al., 2001). 
This report identifies and evaluates the main types of indicators that may be required to inform policy actions. This includes both an evaluation of how existing indicators can be used, and the types of new indicators that can be obtained from existing data sources or which need to be created, such as through new surveys. Section 2 first places the policy-indicator linkage into perspective, by evaluating the policy implications of how biotechnology is defined, the effect of policy goals on the types of indicators that need to be gathered, the main types of policy options available in most OECD countries, and the relevance of currently collected indicators for each policy area. Section 3 reviews indicators for the general economic and social policy implications of biotechnology over the short-term future. Section 4 looks in greater detail at the types of indicators that are required for policy in the three main applications of biotechnology: agriculture, health, and industrial and environmental applications. Section 5 summarizes the proposed indicators in sections 3 and 4 and how these indicators could be collected. Section 6 provides a few general conclusions.

\section{The policy-indicator nexus}

\subsection{The definition of biotechnology}

The first step in any evaluation of the relevance of indicators to specific policy actions is to clearly define biotechnology. There are two main choices, as outlined in the OECD Biotechnology Statistics Framework (OECD, 2001d): a single definition that covers all biotechnology activities and a list-based definition that asks about different types of biotechnologies.

A single, broad definition of biotechnology is complicated by differences in the meaning of biotechnology by sector. In common usage, "biotechnology" in agriculture usually refers to genetic modification (GM) and associated technologies such as DNA markers. It may sometimes include tissue culture, but it never includes traditional technology such as conventional breeding. In contrast, the common definition of biotechnology for environmental and industrial applications mostly includes technologies that do not use GM organisms, such as bioremediation for treating contaminated soils or bio-bleaching of wood pulp. In the health sector, 'biotechnology' refers to several advanced technologies, including genetic engineering, genomics and proteomics, but it can also include technologies, such as combinatorial chemistry, that have applications in traditional chemical synthesis. These differences in what is understood by "biotechnology", both between and within sectors, could explain why respondents to a field test of the OECD's provisional definitions were confused by the single definition of biotechnology (Rose, 2002).

There are several policy advantages from using a single, broad definition of biotechnology in surveys. First, a single definition is useful when space constraints limit the number of questions that can be asked about biotechnology. An example is the inclusion of a question on biotechnology research spending in R\&D surveys. Sectoral differences in the interpretation of a single definition will not be a serious problem as long as the respondent's sector is known and there is some data, from other research, on how respondents interpret "biotechnology". Second, a single definition can help identify the future applications and economic impacts of advanced biotechnology. For example, many of the industrial biotechnologies in use today, such as bio-remediation, bio-bleaching, bio-augmentation, and bio-processing, are technology platforms that can use either GM or non-GM micro-organisms and feedstocks. A definition of biotechnology that is not limited to advanced biotechnologies can capture the potential adoption of GM technology in the future (Arundel and Rose, 1999).

List-based definitions should reduce some of the confusion surrounding a single definition, but respondents can still have problems in deciding if their firm is active in each of the different types of biotechnology (Statistics New Zealand, 2001). A list-based definition of biotechnology is required when the policy 
interest is in the applications and benefits of biotechnology, since many of these will vary by the type of biotechnology in use.

List-based definitions are also helpful when a firm is active in many different sectors. These are usually large, diversified firms. The OECD's list-based definitions can be aggregated into a limited number of categories, such as health, agriculture, and industry. ${ }^{10}$ This can help facilitate comparisons with sector data using the single definition.

\subsection{Policy goals for biotechnology}

It is not the goal of innovation policy to support new technology simply because it is new. As an example, government policy should be neutral as to whether citizens choose to spend their disposable income on mobile phones or on seaside holidays, even though the former is "high" tech while the latter is "low" tech. Policy support for new technology can only be justified if the technology provides public benefits such as improved productivity or quality of life. In this respect, policy actions for biotechnology should be designed to maximize productivity improvements, leading to higher per capita incomes, and quality of life benefits via better health, environmental conditions, and support for sustainable development. ${ }^{11}$

Most of the available indicators for biotechnology do not measure the end goals of interest (the economic and other public benefits), but instead measure intermediate economic effects that may or may not be a step along the way to the end goals. A good example is the comparatively large number of available indicators for small "core" or dedicated biotechnology firms (DBFs) in each country. The assumption behind the focus on DBFs is that more of them are a good thing, with several governments introducing policies to encourage their establishment. Yet, assume that there are two countries, A and B, both of which have 10000 employees active in biotechnology R\&D. In country A, all 10000 researchers are employed by 100 small DBFs. In country B, all 10000 are employed by ten large firms. Does this difference in the location of biotechnology expertise matter? The large number of biotechnology indicators for DBFs suggests that it does. One explanation is that small DBFs play a vital incubator or gateway role between universities and large firms, while large firms are incapable, due to bureaucratic structures and a reluctance to take risks, to undertake these roles themselves (Allansdottir et al., 2001). This may have been true in the first decade or so of biotechnology development in the United States, but is it true today?

This question cannot be answered unless we have data on biotechnology activities across all firms. Unfortunately, it is much more difficult to obtain this type of data for large diversified firms than to obtain data on the numbers and activities of DBFs, which are much easier to identify. Even worse, the availability of indicators on the number of DBFs could encourage policy makers and researchers to largely measure success using this indicator, rather than attempting to measure the economic and social benefits from the application of biotechnology by many different types of firms.

10. More detailed fields are used in the Biotechnology Statistics Compendium (van Beuzekom, 2001). For example, Sweden provides data on health that is divided into diagnostics, drug delivery, and medical technology. Spain divides agricultural biotechnology into plant propagation, plant diseases, bio-pesticides, transgenic plants, and transgenic animals.

11. All of these goals are included in the consultation document of the European Commission Towards a Strategic Vision of Life Sciences and Biotechnology (EC, 2001). Furthermore, the European Commission's proposals for the Sixth Framework Programme stresses quality of life issues, with USD 2.3 billion in research funding earmarked for a new 'Quality of life' category that fuses separate efforts in agricultural, biomedical, and biotechnology research (Laget \& Cantley, 2001). Other national biotechnology strategies stress similar goals. See the Canadian Biotechnology Strategy (biotech.gc.ca) or www.sustainable-development.gov.uk for the United Kingdom. 
The DBF example points to another problem, which is that almost all innovation indicators with an economic basis are based on the assumption that more is better - more R\&D, sales, patents, firms, venture capital investment, etc. are better than less of each of these. This is not always true. A large number of small, undercapitalised DBFs could be less able to commercialise new discoveries than a smaller number of large DBFs with adequate capital reserves. Similarly, high R\&D intensities can be caused by a failure to develop commercially successful products, processes or services, while high venture capital investments can be a mark of an imprudent, speculative bubble.

\subsubsection{Policy options}

The policy options in reaction to biotechnology can be positive, neutral, or negative. The positive policy interests are to encourage the development, adoption, and diffusion of beneficial biotechnology. This could require using government funding to influence the research trajectory. A neutral or "no action" policy stance is appropriate when biotechnology offers no advantages over a non-biotechnology product or process. One problem here is due to the cumulative nature of technological progress. A biotechnology could offer no immediate benefits, but the experience and knowledge gained through its use or development could encourage further investment, or create greater competition. A negative policy reaction - usually expressed through regulation - is appropriate when a biotechnology has the potential to harm the environment, health, or distort markets. Indicators for the end effects of biotechnology, rather than economic intermediaries, are necessary for determining the appropriate option.

We need neutral, unbiased indicators that are of value for assessing policy actions and public benefits. Unfortunately, the choice of indicators is not neutral but will have political implications. For example, potential indicators for bio-pharmaceuticals include the number of new drug approvals for bio-pharmaceuticals (or the percentage of all drugs that are bio-pharmaceuticals), or sales from bio-pharmaceuticals. An alternative indicator, discussed below in section 4.2.1, is a measure of the therapeutic value of new drugs, but this type of indicator is likely to be more controversial than an indicator for the sales of bio-pharmaceuticals.

Data on the costs or negative externalities of biotechnology are difficult to obtain, other than on a case-by-case basis, and can seldom be transformed into indicators. This is because data on the potentially harmful effects of biotechnology are usually based on specialised scientific research. An example is research on the development of insect resistance to Bt corn and cotton. Furthermore, the potential disadvantages of biotechnology are not consistent within a field of biotechnology. For example, there is no consistent data on the problems associated with each type of GM crop. This is because each type of GM crop is unique - insect resistance, for example, does not apply to GM varieties with improved quality

characteristics. Fortunately for policy making, this type of research does not need to be repeated in each country, as long as the results can be generalised to a range of conditions.

\subsection{Linking biotechnology policy and indicators}

This section links specific indicators to general policy options. In order to identify the key indicators for biotechnology of value for policy, we need to know something about the available range of policy options.

The OECD's Biotechnology Statistics Framework (OECD, 2001) divides biotechnology indicators into four main fields defined by the needs of users drawn from government, industry, and academia. The four fields include indicators for 1) the development of biotechnology, 2) the application and use of biotechnology, 3) the economic impacts, and 4) social issues, including the impact of biotechnology on health and the environment (the public benefits) and public perceptions of biotechnology. These four fields are relevant to all conceivable user needs, but they do not directly match the types of policies in use within 
the OECD. This is because current policies focus on the first field (the development or creation of biotechnology) and tend to neglect the other three fields. Therefore, in order to link policies and indicators, this report divide the indicators for biotechnology development into three groups that match the current thrust of policy options within the OECD: 1) supporting biotechnology research, 2) diffusing biotechnology knowledge and expertise among different actors, and 3) supporting the commercialization of biotechnology research.

Several policies are also available for the second field identified in the Biotechnology Statistics Framework: the application and use of biotechnology products and processes. The remaining two indicator groups in the Biotechnology Statistics Framework, economic impacts and social issues, are not directly relevant to a specific set of policies. Instead, the main policy relevance of economic indicators is to assess the application or use of biotechnology. Indicators for social benefits are of vital importance and applicable to every one of the four main policy areas.

The next section briefly summarizes the four main types of S\&T policies that are in widespread use within the OECD ${ }^{12}$ and the types of indicators that can inform these policies. Some of these indicators are available in the OECD report Biotechnology Statistics in OECD Member Countries: Compendium of Existing National Statistics (van Beuzekom, 2001) (henceforth referred to as the Biotechnology Statistics Compendium). Other indicators do not yet exist. The second section turns to the more difficult task of forging a loop between the end results of biotechnology - the applications and benefits - and S\&T policy to support the development of biotechnology.

\section{$2.4 \quad$ Indicators and $S \& T$ policy}

Supporting biotechnology research: There are two main types of programmes to support biotechnology research: direct government funding of research by the public research sector and direct and indirect government funding of research by the private sector. Government funding of both public and private biotechnology research can be substantial, with almost half of all biotechnology R\&D in the United States funded by Government ${ }^{13}$. The Federal US government alone spends an estimated USD six billion per year on biotechnology research (Senker and Zwanenberg, 2000), while approximately USD 3.4 billion (US dollars in PPP) was spent on biotechnology by Europe, Australia, and Canada combined in 1997 (van Beuzekom, 2001).

Relevant indicators for public funding of biotechnology research consist of both basic data on public R\&D spending in biotechnology and intermediate output measures of public biotechnology research, such as patenting by public research institutes and citations to public research papers. Of note, the only consistently available indicator in the Biotechnology Statistics Compendium is for public R\&D expenditures, although

12. An important source for identifying policies is the Trendchart website, funded by DG Enterprise, which provides detailed descriptions of S\&T policy in all 15 EU countries. Another source is the report by Arnold and Kuusisto (2002) on government innovation support in five EU countries plus Korea and Singapore. American policy is less diverse, with a focus on funding research or on regulation. Most of the 12 Federal agencies with biotechnology programmes fund basic rather than applied research, although some state programmes support technology transfer (Senker and Zwanenberg, 2000). Canada and Australia have a proactive biotechnology policy that is more similar to European than American policy. (For Canada, see http://strategis.ic.gc.ca/SSG/bh00127e.html) and for Australia see http://www.biotechnology.gov.au/ Industry_Research/National_Strategy/national_strategy.asp.)

13. There are few signs yet that the US government plans to reduce its support for biotechnology research. As an example, a recent US Congressional Report (2001) recommends increasing the use of plant genomics by agricultural experimental stations, which will either require new funding or shifting previous funds from non-biotechnology research. 
data are not given for the United States, since only rough estimates are available. Other indicators, such as for patenting and citations, are not separated into public and private sources. This is not much of a problem for citations, since over half of the citations will be to articles that involve a researcher from public science, but an indicator for biotechnology patents from public research would be useful. ${ }^{14}$

Most countries also finance biotechnology $R \& D$ by private firms, either via direct subsidies for biotechnology R\&D (for example the Framework Programme in Europe) or via tax credits. These are available to all sizes of firms. In addition, many European countries provide additional subsidies for small firms, such as soft loans and direct grants for innovation (33 different policy measures in the European Union). American support is largely limited to basic research by public sector organisations, but a few programmes, such as NIST (National Institute of Standards and Technology), can subsidise biotechnology research by small firms.

The Biotechnology Statistics Compendium includes several relevant indicators on the target of these policies (mostly DBFs). These include the number of DBFs and their employment, research expenditures, and field of activity. Several crucial indicators are rarely available. These include the percentage of DBFs receiving research subsidies and the share of their total research spending (or total revenues) that is funded from government sources. The latter indicator would provide a measure of the economic viability of DBFs in the absence of government subsidy. Such an indicator would be of value in comparing American and European DBFs. The rapid growth in the number of European DBFs, combined with their small average size, suggests that they could be heavily dependent on government subsidies, and possibly more so than their American counterparts. If true, it would indicate that the rapid growth in European DBFs may not be sustainable.

Diffusing biotechnology knowledge and expertise: Many public policies provide incentives for collaboration in order to diffuse knowledge and expertise among different actors. These include subsidies to private firms to contract research out to public institutes, passive incentives to increase the number of contacts between public research and private firms, and research subsidies for private firms that require collaborative networks.

The Biotechnology Statistics Compendium includes several indicators for the dissemination of knowledge, including patent data (although a better indicator would be the use of patent databases), citations, biotechnology alliances, and indicators for co-patenting and co-publishing.

Commercialising biotechnology research: Policy makers in several OECD countries believe that firms in their country lag behind the United States in their ability to commercialise national biotechnology research efforts. The result has been the development of a variety of policies to encourage commercialisation. Several EU countries, including Austria, Belgium, Germany, Denmark, Finland, France, Italy, the Netherlands, Sweden, and the United Kingdom, provide subsidies or grants to increase seed and start-up capital for small biotechnology firms, including university spin-offs and start-ups. They include guarantees for seed and expansion venture capital, the provision of managerial expertise, equity investment, high-risk loans, and tax relief for private venture capital investments in high technology areas such as biotechnology. Korea has also introduced similar policies, although not specifically focused on biotechnology. Since the

14. A current OECD project has used surveys to estimate the share of all patent applications by the public research sector that are in health fields. Biotechnology could account for a significant fraction of this group. The percentage of all patents in health and biotechnology fields in 2000 or 2001 is $49 \%$ in the Netherlands, Italy and Denmark, 37\% in Switzerland, 36\% in Korea, and 25\% in Japan and Germany (OECD, 2002). Nesta and Mangematin (2002) identify the percentage of patents in the Derwent Biotechnology Abstracts (DBA), from 1975 to 1998, that are from the public research sector. The public sector share in 1998 was $37.3 \%$. Nesta and Mangematin do not provide results by country, but this should be possible to calculate for most of the 40 patent jurisdictions covered in the DBA. 
mid 1990s, the German government has provided substantial funds for venture capital, loans for seed capital, and state equity investment as part of its "Bio-Regio" programme.

The Biotechnology Statistics Compendium includes only a few indicators for the commercialization of biotechnology research. Relevant indicators include venture capital investment, alliances (if limited to between firms and public research institutes), the licensing activities of Technology Transfer Offices (TTOs), and the number of biotechnology spin-offs.

Encourage the adoption (application and use) of biotechnology: Policies to encourage the application and use of biotechnology include procurement, demonstration projects, information programmes, and technology adoption subsidies. Many of these, such as information programmes, are targeted towards small firms. Several countries fund demonstration or technology centres that provide management advice, technology audits, and technology feasibility programmes, such as the BIO-WISE programme in the United Kingdom, which provides information to SMEs on the application of biotechnology and subsidies for demonstration projects (Arnold and Kuusisto, 2002). In the United States, manufacturing extension centers can provide these services. Other methods are subsidies for small and medium-sized enterprises (SMEs) to hire scientists, engineers and technicians. A few countries, such as Greece, provide direct subsidies for firms to adopt innovative manufacturing technologies. In addition, agricultural extension services in many OECD countries can provide advice to farmers on the adoption of GM crops.

Very few of the available indicators in the Biotechnology Statistics Compendium cover the adoption or diffusion of biotechnology, with the notable exception of some of the statistics collected in Canada and New Zealand on the use of specific biotechnologies, the share of total revenues from biotechnology sales, and indicators for the diffusion of GM crops. We could use indicators for how many technology centres provide advice to SMEs on the adoption of biotechnologies, and indicators for the use of biotechnology applications by firms across the OECD.

\subsubsection{Forging a loop between indicators and policy}

The Biotechnology Statistics Compendium provides an extensive array of different biotechnology indicators. In order to assess their applicability to different policy options, this section evaluates the usefulness of many of these indicators for the four main policy areas discussed above, plus indicators for the social benefits of biotechnology, which are of use to each of the four policy areas. The results are given in Table 1, sorted by the availability of each indicator across the OECD. All of the indicators in Table 1 are collected in at least one OECD country. Indicators with a "high" rating are available for 15 or more OECD countries, those with a "medium" rating are available for four to 15 countries, and those with a "low" rating are available for three or fewer countries. The table does not list all of the variations in the available indicators, but assigns them to main types, such as "patents granted" or "trade in biotech/biotech exports".

The last column in Table 1 provides information on the source of the original data for constructing each indicator. ${ }^{15}$ There are four main types of organizations that collect data: government or international public organisations (GOV) such as the USPTO or EPO, national statistical offices (NSO), academics, usually based at universities or semi-independent public research organisations (ACD), and private organisations,

15. All biotechnology indicators are derived from innovation statistics, which provide data on activities such as $\mathrm{R} \& \mathrm{D}$ expenditures, patent applications, or the number of DBFs. Indicators manipulate statistics to provide meaningful and comparable measures of biotechnology activities. Examples include per capita patent rates, national shares of biotechnology citations, or the percentage of cropland planted to GM crops. In many cases, the organisation that analyses the statistics to produce the indicators is not the same as the organisation that collects the statistics. 
such as consultants or industry trade groups (PRI). In some cases, the indicator is collected by more than one type of organization. For example, both NSOs and private firms collect data on biotechnology employees by field. However, NSOs can provide more accurate data than private firms, which is why they are listed first.

Table 1 shows that most of the widely available indicators in the Biotechnology Statistics Compendium are relevant to biotechnology research. This is as expected, both because S\&T policy has been focused on funding biotechnology research, and because biotechnology is a new field, with only a limited number of applications to date. However, if biotechnology is to live up to its promise, the number of applications should start to rise rapidly, and with it the social benefits or costs. This means that indicators for applications and benefits should increase in importance.

None of the widely available indicators are of a high value for measuring the application or benefits of biotechnology, with the exception of the indicator for GM field trials by trait, which is an indicator of future benefits and applications. However, there is a better supply in the medium availability category. An evaluation of both the application and benefits of biotechnology requires data by field of application. There is a good start in this area for agricultural applications, with data on the area planted to GM crops by trait. Some data are also available for both public and private R\&D funding by biotechnology field, although these indicators are less useful, because there is no guarantee that the future applications or benefits will be commensurate with current R\&D investment patterns. Two of the most useful indicators - biotechnology revenues by field and the types of biotechnology applications (in use) by firms, are only available for a few OECD countries.

Some of the indicators are of little or no direct relevance to the design of specific policies, such as indicators for patent and citation share, or the number of biotechnology firms. The former are largely measures of national capability. They can indicate if a country is lagging behind others, but they provide little information for specific policies. Nevertheless, these types of indicators have two applications for policy. First, they can help governments decide if they need to introduce a range of policies to promote national capabilities in biotechnology. This decision partly depends on whether or not biotechnology will be a strategic technology in the future. Second, patent or citation indicators could be used as an output measure of the success of government programmes to promote biotechnology research.

Indicators of the number of biotechnology firms can be misleading for policy unless there is some adjustment for differences in firm size. The effect of a large number of small firms on employment, economic outputs, or research capabilities can be less than the effect of one large firm, as noted above. However, simple counts of the number of small biotechnology firms, or DBFs, could be of value to the investment decisions of private firms.

The results in Table 1 indicate that a few indicators for the application and benefits of biotechnology are available, but only in a limited number of countries. Clearly, there is a need to increase both the range and availability of these types of indicators. This is necessary in order to feed information on applications and benefits into the decision making process for the development, dissemination, commercialization, and application of biotechnology. 


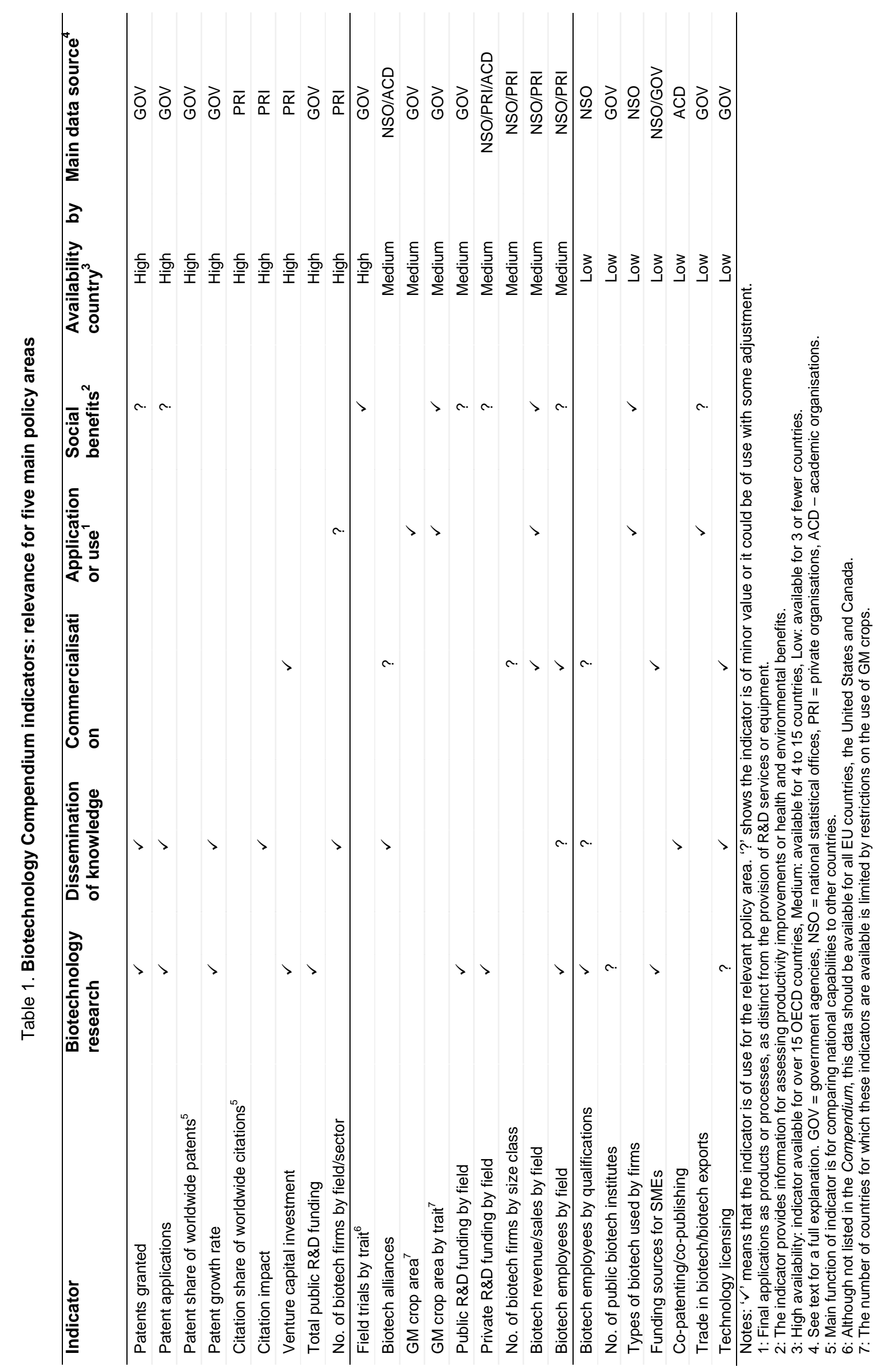




\section{Main policy issues}

This section evaluates some of the major policy questions for biotechnology in general. In addition, the social acceptance of biotechnology is briefly discussed. Where applicable, this section evaluates existing indicators of relevance to each policy issue (drawn from the Biotechnology Statistics Compendium), suggests new indicators that can be constructed from existing data, or suggests new indicators that would require new data collection, such as in future biotechnology surveys.

\subsection{How pervasive or strategic is biotechnology?}

As noted in the introduction, one of the main justifications for public support for biotechnology is that it is a pervasive technology that could play a strategic role in economic development. Although we have several indicators for public and private investment in the creation of biotechnology innovations, we know a lot less about the actual use of biotechnology, or its application. It is not possible to determine the pervasiveness of biotechnology without indicators for its application.

A comparison with available data in ICT is instructive. In addition to data on R\&D and employment in ICT sectors, the supply of S\&T indicators has rapidly followed the development of new ICT applications. We have internationally comparable data on mobile phone penetration rates, Internet access, broadband Internet access at home, Internet sales, software sales, the percentage of the working age population that has taken a computer course, the percentage of school classrooms with computers, the use of different types of ICT at work, and many, many other indicators.

Currently, data on the fields of biotechnology research provide a rough outline for the potential applications of biotechnology, but we do not know enough about how and where these applications will be used, or how they are changing over time. Evaluating the application of biotechnology will be complex because of the role of competing technologies. As a process innovation, biotechnology must compete with both existing processes and with potential improvements to them (Werner and Reiss, 2001). A good example is the application of biotechnology in the pulp and paper industry, where both large investments in existing equipment, familiarity with chemical and mechanical production methods, and technical difficulties in developing competitive biotechnology processes hinders future applications (Laestadius, 1998).

Indicators for the pervasiveness of biotechnology are of value to many different policy issues on the economic impacts of biotechnology, including the need for specific job skills, job creation, and job losses. In order to construct useful indicators, we need data on the application of different types of biotechnology by all firms in sectors where biotechnology has current or future applications. The Biotechnology Statistics Compendium includes relevant indicators for Canada and New Zealand. We also need data on alternative, competing technologies, and on the barriers to adopting biotechnology.

A second issue that is related to the pervasive quality of biotechnology is its commercial viability without public subsidies. An answer to this question is particularly relevant to European policies to support DBFs. We need an indicator for the share of DBF revenues from public funding sources, by field of activity, and how these are changing over time. It would also help to have an internationally consistent definition of a DBF. Currently, the definition of a DBF appears to vary by country - even among the national Ernst \& Young reports.

The third relevant issue concerns biotechnology trade or exports. Indicators for these are of relevance to terms of trade issues, which is one of the reasons for supporting national capabilities in strategic technologies. The Biotechnology Statistics Compendium contains trade data for the United States, plus data 
from Canada, derived from a survey of firms, on biotechnology exports by type of application. The data for the United States is of less value, however, because the definition of biotechnology includes many non-biotechnology products. However, many OECD countries may be reluctant to obtain trade (or other) data from surveys. Other options include trade in intellectual property (license rights, etc.), but this type of data is not very reliable, since multinational firms can manipulate license payments in order to reduce taxes. $^{16}$

\subsection{Dissemination of knowledge}

The dissemination of knowledge and expertise in biotechnology involves both knowledge used in R\&D and knowledge used in the application of biotechnology. (The latter is usually viewed as part of the diffusion of a new technology). This section is limited to policy issues for the former case.

Following the example of the United States after the 1980 Bayh-Dole Act, many OECD countries have altered their rules to permit patenting by public research institutes and to encourage patenting and licensing, via the establishment of technology transfer offices (TTOs) (OECD, 2001a). In addition, the types of discoveries that could be patented were broadened in several jurisdictions, such as the United States, to include life forms and gene sequences. In the late 1990s, several economists and scientists suggested that the patenting and licensing activities of both public research organizations and firms, partly in response to these policy and legal changes, could be interfering with biotechnology research, thereby retarding progress ${ }^{17}$. Interference could occur from the strategic use of patents by firms to block competitors, the cost of assembling highly complex licensing agreements to pursue particular areas of research (Heller and Eisenberg's 1998 "anti-commons" thesis), the length of time required to negotiate licenses, both the direct costs of litigation and the indirect costs due to the loss of time of researchers and managers, and the possibility that either exclusive licenses from universities or some types of patents could limit the diversity of approaches to a problem and consequently reduce the probability of success. An example of the latter is the extension of patent rights in the United States to gene sequences, even when the patentee does not know what the gene is for (Nuffield, 2002; Williamson, 2001). These patents will block competitors from working on the same genetic construct.

Effective IPRs are essential for the current commercialization strategies of biotechnology firms, although there is some argument over whether this was the optimum route to take (Fisher, 2001) ${ }^{18}$. The argument in support of university patenting is that the types of inventions developed by these institutes are "embryonic" and require considerable further development before they can be commercialized (Mowery et al., 2001). Under these conditions, a firm may not be interested in further developing the invention unless it has an exclusive license $^{19}$. This may be true for some inventions, but in other cases of exclusive licenses, such as

16. The biotechnology trade data for the United States is based on a handful of the thousands of product categories in the Harmonized System (HS). Most of these categories are drawn from two two-digit classes: organic chemicals and pharmaceutical products. Another alternative is to use product categories that include biotechnology equipment. However, this does not appear to be a feasible option, given the broad product categories in the HS for scientific equipment.

17. See, for example, Bobrow and Thomas, 2001; Cowan \& Harison (2000); David (2001); Fisher (2001); Heller \& Eisenberg (1998); Jaffe (1999); Kingston (2001); Mazzoleni and Nelson (1998); Verspagen (1999); and Walsh, Arora and Cohen (2001).

18. An alternative path would have been to keep biotechnology research for a longer period within the public domain, leaving commercialisation to a later stage, and based on much narrower patents that would be less successful in blocking competitors.

19. About half of university licensing in the United States is on an exclusive basis (AUTM, 2000). In contrast, only $14.3 \%$ of licenses from the National Institutes of Health (NIH) were exclusive (GAO, 1999). 
for patents on genes, the effect may be to hamper both academic and commercial research (Williamson, 2001), leading to few public benefits.

These problems are thought to be particularly acute in biotechnology, since biotechnology and health account for about $35 \%$ of all university patents in the United States, and much of the growth in university patents over the past decade (AUTM, 2000). In the Netherlands, Italy and Denmark, biotechnology and health accounted for $49 \%$ of university patents in 2000 (EZ, 2002; OECD, 2002). Biotechnology policy needs to address both the concerns over biotechnology patenting by public research organizations, and the wider concern about the possible negative effect of IPR policy on scientific progress, including gene patents and patent breadth. The main issue is how to ensure that pre-competitive knowledge is freely available, while respecting the rights of firms to receive a fair return on their investments. Theoretical economics provides some clues on these issues, ${ }^{20}$ but there is also a serious need for better indicators.

Indicators for the patenting and licensing activities of universities are currently under development in several OECD countries, using surveys of TTO managers at universities and other publicly funded research organisations. A first requirement is for data on university licensing and patenting by technology field, so that biotechnology patents can be identified. This can be supplemented with data on biotechnology patents from patent databases, as in the Biotechnology Statistics Compendium. Patent data may need to be provided both with and without patents for gene sequences. This is because gene discovery is routine, with thousands of potential patents that provide almost no information on future inventions. Data excluding gene patents (including expressed sequence tags (ESTs) and single nucleotide polymorphisms SNPs)) would also improve comparability between patents at the USPTO, where the threshold for non-obviousness and a credible industrial application for gene patents are very low, and at the EPO, where these thresholds are much higher (Nuffield, 2002). A second requirement is for indicators on the effect of patent blocking on research projects, and the costs and difficulties in acquiring necessary licenses. This type of data can only be obtained from surveys.

It would be useful to acquire similar data on the effect of patents and licenses on the research activities of firms, possibly by adding additional questions to existing biotechnology surveys. The Statistics Canada and New Zealand biotechnology surveys included a question on whether or not a project had to be abandoned (or not started) because of patent rights held by another organisation. In Canada, approximately $16 \%$ of biotechnology firms reported that they had to abandon an R\&D project, while in New Zealand about $8 \%$ of firms noted interference from IPRs, although this question covers all biotechnology activities, rather than only R\&D projects (Statistics New Zealand, 2001). ${ }^{21}$

Walsh et al (2001) used a series of 45 interviews to explore the effect of patenting and licensing on the R\&D activities of both firms and universities in the United States. They found that the anti-commons problem did not appear to be very serious, although this was often due to widespread patent infringement. They identified several other problems that could reduce the efficiency of R\&D or create social welfare costs: the cost of litigation, time delays in negotiating licenses, and limits on the variety of approaches to a research problem. Their research provides a useful starting point for developing questions on these issues that could be added to larger-scale surveys.

20. See, for example, the reviews of the theoretical literature on the effect of patent width and licensing on innovation incentives by Gallini and Scotchmer (2001) and by Bessen (2000).

21. The $8 \%$ is calculated on the basis of all 180 firms in New Zealand that use biotechnology in some way. Once limited to responses from R\&D performing firms, the percentage rises to $19 \%$. 


\subsection{Human resources}

Relevant policy issues for human resources include: Is the supply of trained scientists and engineers adequate? Is the nation losing more experienced researchers to other countries than it is gaining (the dreaded "brain drain"), and are private R\&D units pulling up stakes and shifting to other countries, perhaps in response to a hostile regulatory environment? Indicators for the first question can be obtained from biotechnology survey questions on the problems facing firms. An answer to the second question requires indicators on the current stock of researchers, the supply of new researchers, and information on their country of origin and their reasons for moving. ${ }^{22}$ The third question is not suitable for indicators. Interview techniques are more appropriate.

\subsection{Social acceptance of biotechnology}

A major policy concern in several countries, particularly in Europe for agricultural biotechnology, is that public opposition to biotechnology could block its future development and application. Although not included in the Biotechnology Statistics Compendium, excellent indicators on public opinion and attitudes to biotechnology are available from surveys for several countries. These include the Eurobarometer surveys for Europe (Gaskell et al., 2000) plus surveys for the United States (Priest, 2000) and Canada (Einsiedel, 2000). ${ }^{23}$

All of these surveys convincingly show that public support for biotechnology hinges on its benefits. ${ }^{24}$ In Europe, support for pharmaceutical applications is very high, where the benefits outweigh the risks, while support for the available agricultural applications to date is very low, where there are almost no detectable benefits for consumers or for farmers due to Europe's large agricultural subsidies ${ }^{25}$. Consequently, the European public's concerns over the possible risks of agricultural biotechnology, even though remote, could be viewed as rational, given the extremely small public benefits of the types of GM crops commercialised so far.

An analysis of biotechnology policy by Levidow and Marris (2001) notes that science and technology policy in many OECD countries invokes technological imperatives - the failure to adopt a technology will result in a decline in economic competitiveness. Whether or not public opposition to biotechnology could lead to this type of outcome depends on whether or not biotechnology is a strategic technology in each application facing opposition. The answer to this question for agricultural biotechnology, as with several other applications, is not yet known, but could be obtained from better indicators. Furthermore, if the benefits of any technology are the primary motivator for public support, then more work to both develop

22. DG Research of the European Commission is funding a study by Wendy Hansen, International Mobility of Human Resources in Science and Technology, to collect relevant data on these issues from individual researchers and scientists.

23. A survey for Japan in the same issue of Nature Biotechnology as the Gaskell et al. study is based on too few responses to be reliable.

24. Academic discussion of public opposition to new technology has tended to stress either a deficit model (the public is ignorant of science) or more recently a trust model (the public does not trust public regulators (Levidow and Marris, 2001). The deficit model is out of favour for biotechnology because of opinion survey results which show a complex relationship between knowledge about biotechnology and opposition - in many cases opposition is higher among better informed respondents.

25. Even in other countries, the expected economic and food production benefits over the next decade from herbicide resistant and Bt corn, cotton or soybeans are very low, measuring only a few percentage points higher than what could be achieved through non-GM varieties. See the econometric analyses in the collection of papers assembled in Nelson (2001). 
and analyse indicators for benefits are clearly called for. The next section on the major applications of biotechnology focuses on different indicators for measuring the benefits of biotechnology.

\section{Policy issues and indicators for major applications}

\subsection{Agriculture}

Agricultural biotechnology includes both food crops and crops for industrial feed-stocks. Although agriculture accounts for a small share of total biotechnology $R \& D^{26}$, it potentially has much greater direct and indirect economic effects than biotechnology in health fields. Worner and Reiss (2001) estimate that that about $70 \%$ of all biotechnology related employment in Germany between 2005 and 2010 will be in the agro-food sector.

The two main goals of European agricultural policy ${ }^{27}$ are to retain competitiveness and support sustainable agriculture, with subsidiary goals of preventing rural depopulation, encouraging environmental stewardship through subsidies, and reducing pollution of waterways from fertilizer run-off and pesticides. These goals, with the possible exception of preventing rural depopulation, will be applicable to most OECD countries.

Biotechnology offers a panoply of technical options for meeting agricultural policy in OECD countries, such as replacing pesticides with pest resistance, and creating higher-value crops for both food processing and industry, which could improve farm incomes (Carr, 2003) ${ }^{28}$. Other potential targets for agricultural biotechnology, such as substantially higher yields or nitrogen fixation in cereals (Ruttan, 1999), are less relevant to the OECD than to developing countries. ${ }^{29}$

Many of the goals of agricultural biotechnology can also be achieved through other plant breeding techniques. For example, European and multinational seed firms switched from an emphasis on higher yielding varieties to pest resistance in the early 1990s, largely using conventional breeding technology (Tait et al., 2001). The application of biotechnology techniques such as gene marker technology to conventional plant breeding can both speed up the development of new seed varieties and increase the range of technically feasible options.

26. And an even smaller share of venture capital, with only $1 \%$ of venture capital in 2001 for biotechnology going to agriculture (Sechler, 2001). Highly competitive markets for agricultural commodities does not leave much of a profit margin for innovation, especially by small firms.

27. See the Common Agricultural Policy 2000.

28. For overviews of the potential of agricultural biotechnology, see the PEW (2001) and US Congress reports (2001). Fernandez-Cornejo and Mcbride (2000) provide an analysis of the effects of HT cotton and HT soybeans on US farm incomes. The former increased farm incomes while the latter had no effect.

29. Of note, the claim that agricultural biotechnology will "feed the world" is seen as naïve by many of the managers of Europe's 14 largest seed firms, who were interviewed about the future applications of biotechnology (Tait et al., 2000). Most research on GM crops is in pest resistance and herbicide tolerance. Only $1.1 \%$ of all EU and US GM field trials combined are for yield traits (Arundel, 2002a). 


\subsubsection{Policy issues and indicators for agricultural biotechnology}

Carr (2003) concludes, on the basis of an extensive study on European seed firms, that if agricultural-biotechnology is to contribute to sustainable agriculture, "its developers and users will need strong policy guidance". She comments that we need a "coordinated and systemic policy framework in which sustainable development is a primary and unambiguously defined aim". In order to assess both the need for and the success of such policies, we also need good indicators on the direction of research by both public organizations and private firms active in the agro-chemical sector.

Some relevant indicators are available, using the field trial databases of GM crops in Europe, the United States, and Canada ${ }^{30}$ The field trial data is similar to patent data in that it provides a record of the different types of research projects conducted by firms. The field trial data has one advantage over patents, in that firms are unlikely to conduct field trials unless they are relatively confident that the variety can be commercialized. Due to the time lag between field trials and commercialization, the field trial data provide an indicator of varieties that could be commercialized within two to five years. In contrast, patents are a much poorer indicator of innovations because not all innovations are patented (while all GM crops to be grown outdoors must be field tested). The main disadvantage of the field trial data is similar to that of patents; there is no direct correlation between the number of field trials (or patents) and the number of commercialized GM plant varieties (or patented innovations). As an example, several hundred field trials were conducted in the United States to test tomato varieties that ripened without becoming soft. In contrast, only 15 field trials were required to develop a viral-resistant variety of papaya.

In addition, the interest of agricultural ministries in many countries on the environmental and economic effects of GM crops means that we also have some data on the number of hectares planted to GM crop varieties by trait, although these data are often based on estimates from commercial seed sales. Data quality would be improved by collecting consistent data on an annual basis from farmers for all GM crops, including horticultural crops. The Biotechnology Statistics Compendium includes two basic indicators drawn from the field trial data plus a few indicators using the crop data. These permit an evaluation of the types of GM crops that should be ready for the market in the near future and the possible benefits from their use. This information could be fed back into S\&T policies in order to influence the trajectory of agricultural biotechnology in socially-beneficial directions.

In the same way that patent data can be manipulated to create a wide range of useful indicators, the GM field test data can provide many more indicators of value to policy, such as identifying the location of GM expertise (Menrad et al., 2002). As an example of how the GM field test data could be used, Table 2 provides the percentage of all US and EU field trials in five main trait categories ${ }^{31}$. The greatest interest, in terms of public benefits, is in "second generation" traits for improved product quality, which can potentially provide the greatest benefits to farm incomes and to the environment. These account for $19.2 \%$

30. The European data is available from the Joint Research Council of the European Commission, who provides it on-line as the Summary Notification Information Format (SNIF). The American data is available from APHIS. Two other OECD countries with substantial research in GM crops are Canada (with more field trials than all EU countries combined) and Australia. Canadian field trial data are available at http://www.inspection.gc.ca/english/plaveg/pbo/triesse.shtml and Australian data at http://www.health.gov.au/ogtr/gmorecord/index.htm. In the near future, it may be worth monitoring field trials in several non OECD countries, including China, Brazil, India and Argentina in order to get a complete picture of future GM crops.

31. The results are for trial-trait combinations. For example, a field test for two traits, herbicide tolerance and pest resistance, is counted twice. Menrad et al. (2002) provide slightly different results based on the same data. The differences are due to how multi-year field trials are counted. 
of all US and $12.7 \%$ of all EU field trials. The European public sector accounts for an above average percentage of the agronomic and product quality traits.

A second use of the GM field test data is to calculate changes over time in the focus of research into GM varieties. Figure 1 provides two-year running averages for the percentage of 9122 American field trials in five trait categories between 1991 and $2001^{32}$. The share of trials for pest resistance has remained relatively steady, at between $38 \%$ and $43 \%$ of all trials. Figure 1 divides the quality traits into two groups: food processing and other product quality traits, and industrial and environmental quality traits. The share of trials for food processing traits peaked in 1995 and has since declined, but there is a small increase in the share of all trials for industrial and environmental traits, from 1\% in 1992 to $3 \%$ in 2001.

Table 2. Distribution of EU and US field tests by trait

\begin{tabular}{lrrrrrr}
\hline & \multicolumn{3}{c}{ United States } & \multicolumn{2}{c}{ European Union } \\
\cline { 2 - 7 } Trait category & $\mathbf{N}$ & \multicolumn{3}{c}{$\begin{array}{c}\text { Public sector } \\
\text { share }\end{array}$} & $\mathbf{N}$ & \multicolumn{2}{c}{$\begin{array}{c}\text { Public sector } \\
\text { share }\end{array}$} \\
\hline Herbicide tolerance & 2509 & $(27.5 \%)$ & $4.9 \%$ & 980 & $(48.0 \%)$ & $9.5 \%$ \\
Pest resistance & 3800 & $(41.7 \%)$ & $16.3 \%$ & 477 & $(23.4 \%)$ & $18.7 \%$ \\
Other agronomic & 394 & $(4.3 \%)$ & $25.3 \%$ & 86 & $(4.2 \%)$ & $61.6 \%$ \\
Technical & 669 & $(7.3 \%)$ & $47.3 \%$ & 238 & $(11.7 \%)$ & $14.7 \%$ \\
Product quality & 1750 & $(19.2 \%)$ & $15.6 \%$ & 259 & $(12.7 \%)$ & $29.0 \%$ \\
& 9122 & $(100 \%)$ & $15.0 \%$ & 2040 & $(100 \%)$ & $16.9 \%$ \\
\hline
\end{tabular}

Source: Arundel, 2002b.

Several conclusions of relevance to policy can be drawn from these results. First, the focus of private sector research is not in quality traits, particularly in Europe ${ }^{33}$. In the United States, the private sector appears to have lost interest in food processing traits after 1996, although there is a slight increase in industrial traits. Conversely, the European public sector is focused on agronomic and product quality traits. Several options are available for policy makers to close the loop between public benefits and S\&T policy: they could increase public sector investment, or they could seek out the reasons why private sector investment in these types of traits has not increased.

Cost of GM Technology: A second policy issue is the increasing level of concentration in the agricultural biotechnology sector (Fulton and Giannakas, 2001) and its possible links to a decline in the diversity of agricultural crop varieties. A very useful indicator in this respect would be the average cost of introducing a GM trait into a plant variety. We know that the cost cannot be excessive because some mid-sized seed firms have developed GM varieties. However, there is no consistent data at all on this question. Its answer could be of value in assessing the impact of mergers on competition. Firms have partly been justifying these mergers on the high cost of biotechnology R\&D, but we don't know if these costs are so high as to

32. The EU results (not given) show little change over time for each trait class. Herbicide tolerance tops the list, with between $45 \%$ and $50 \%$ of all field trials. Product quality traits reached a minor peak in 1997 at $16 \%$ of all trials, and have since declined slightly to $12 \%$ in 2001.

33. However, a recent increase in private sector investment in quality traits will take several years to show up in the field test data. Firms first develop new GM varieties in the laboratory, then conduct their initial trials in greenhouses. The field test data contains no information on either of these activities. A very interesting study by Menrad et al. (2002) surveyed firms and public research organisations to identify the types of GM varieties that are in the pre-field trial stage. Although the results may not be entirely representative due to low response rates, they suggest that quality traits account for a higher percentage of such early stage research projects than for field trials among both private firms and the public sector. 
justify mergers. Furthermore, the cost of developing GM varieties should be declining over time, as firms develop familiarity with the technology and as genome libraries reduce the time required to find useful gene constructs. This could open more doors for small seed firms, and increase the ability of firms in developing countries to use biotechnology. ${ }^{34}$ Questions on the cost of GM could be included in biotechnology surveys. To be most useful, this type of information would need to be collected over time.

34. Assuming that the cost of licensing the rights to patents on basic biotechnology techniques or genes is not prohibitively expensive. 


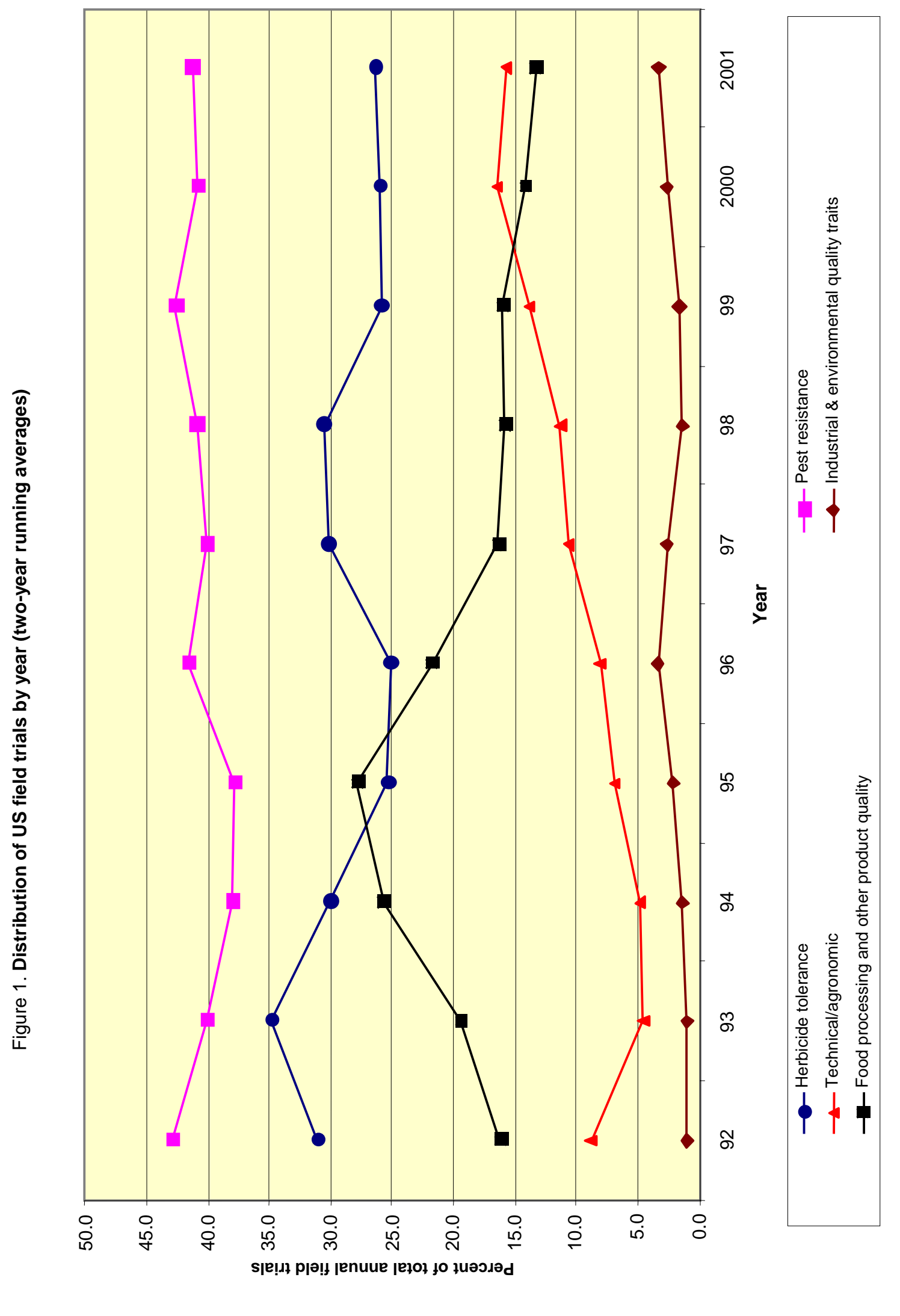


Competitive alternatives: The third area where more indicators are required is on technologies that provide a competitive alternative to GM crops. These include non-GM varieties, different types of GM varieties, or non-agricultural substitutes. For example, phosphorous pollution in waterways from pig and chicken manure can be reduced through GM feed that contains phytase (an enzyme that allow these species to digest phytates in their feed), by genetically engineering pigs and chickens so that they express phytase in their saliva, or by adding phytase to feed. Which option is chosen will depend on the relative costs and benefits. In some cases, GM crops may never offer the most cost-effective solution, due to high identity preservation ${ }^{35}$ costs.

There are several major policy implications of competitive alternatives to GM varieties, particularly when the competition between biotechnology and other technologies involves environmental costs and benefits. The first issue concerns the justification for subsidies to develop GM varieties, for example by preferentially supporting research into a biotechnological solution to a problem rather than the use of a different technology. A second issue concerns the use of policies to promote the adoption of biotechnological solutions versus alternatives. The latter include everything from promotional materials to demonstration projects.

How to identify the optimum policy approach will be particularly difficult when biotechnology is not commercially viable over the short term, but is thought to offer advantages over the long term ${ }^{36}$. In some cases, there may be no accurate method of estimating the long-term advantages of biotechnology versus alternatives. In other cases, such as the example given above, the best policy response may be open-ended regulations that provide an incentive for firms to find a solution without specifying the type of solution. Then, the optimal technology can be developed through market competition, without policy favouring one option over another.

The question for indicator development is how to obtain useable indicators for these policy issues. Perhaps the only feasible option is to include relevant questions in surveys on the use of biotechnology by firms active in an entire sector (the survey must not be limited to firms that already use or perform research in biotechnology). Firms that do not currently use biotechnology can be given a series of questions for their failure to do so. These questions should probe the cost of biotechnology versus alternatives, plus other reasons for preferring alternative technology, such as past investment or knowledge and information barriers to the adoption of biotechnology.

\subsection{Biotechnology and health}

The lion's share of public investment in biotechnology research goes to health applications. The Government role in many OECD countries in funding health biotechnology and in providing public health coverage ensures a need for indicators on the outcomes of health biotechnology. The main policy issue is if the large public investments in health biotechnology are producing equivalent public benefits.

Relevant indicators include output measures for the number of diagnostics, bio-pharmaceuticals for treating diseases, vaccines, and several other minor categories ${ }^{37}$ that are either in the development pipeline

35. This is cost of keeping a GM crop variety separate from other varieties. These costs extend from the farm where the crop is grown to the final user.

36. This is similar to the problem facing public subsidies for renewable energy resources such as wind power, which was considerably more expensive than conventional energy sources during its early development, but has become increasingly competitive over time as research and experience reduced the cost per KWH.

37. Recombinant rattlesnake anti-venom is an example of an "other" category. New delivery methods for drugs are usually classified under pharmaceuticals. 
or approved for use. The Biotechnology Statistics Compendium does not include these indicators, but it would be relatively simple to include them in future editions, since stringent regulations require notification of Phase 1 through III trials. Market approval notifications are available from regulatory agencies such as the FDA in the United States or the EMEA ${ }^{38}$ in Europe. These types of indicators are readily available on a national basis. Data on the number of bio-medicines under development in each country (adjusted by public and private R\&D spending or research employment) can be used as an indicator of the efficiency of the health biotechnology sector. ${ }^{39}$

A second indicator, although of greater value to private investment decisions, consists of sales data for bio-pharmaceuticals, diagnostics, etc. This type of data is currently collected by private organizations, but coverage is erratic and largely limited to the best-selling bio-pharmaceuticals.

\subsubsection{Indicators for therapeutic value}

Indicators for sales, the number of biotechnology drugs in the drug pipeline, or the number of bio-pharmaceuticals that have received market approval, are useful measures of economic efficiency or the financial viability of biotechnology firms, but they are of less value for assessing the public benefits of health biotechnology. For instance, sales data would only be useful if there was a strong positive correlation between sales and benefits. Although such a correlation probably applies to agricultural and industrial biotechnology, it is unlikely to apply to pharmaceuticals because of severe market distortions from acute information asymmetries, extremely elastic consumer demand, and monopoly pricing. Furthermore, the public benefits of pharmaceuticals do not derive from the amount of consumption per se, but from their therapeutic benefits. What we really want to know is if the large public and private investment in biotechnology has created new drugs that offer therapeutic advances over existing drugs.

The number of bio-pharmaceuticals that have received market approval is also an unsatisfactory indicator of public benefits. A drug will not receive market approval unless it has passed requirements for safety and efficacy, which suggests that this indicator has some value. However, efficacy is mainly determined from comparisons with placebos, rather than against existing drugs. ${ }^{40}$ One consequence is that many drugs that receive market approval are "me-too" drugs that offer little or no therapeutic advance over drugs already on the market, although they could theoretically provide consumer benefits by increasing price competition. Although the development of "me-too" drugs is a viable commercial strategy for pharmaceutical firms, it is not a very satisfactory outcome for public investment.

There are several possibilities for indicators of therapeutic benefits that go beyond the number of bio-pharmaceuticals with marketing approval. Ashton (2001) uses commercial data to calculate that 56\% of the bio-pharmaceuticals launched between 1982 and 2000 in the United States were for orphan diseases, compared to $14 \%$ of other pharmaceuticals. He also reports that $25 \%$ of bio-pharmaceuticals had a unique mode of action, compared to $15 \%$ of small chemicals. These two indicators provide good evidence that

38. European Agency for the Evaluation of Medicinal Products.

39. There are a few difficulties, however, in defining a bio-pharmaceutical. Both public sources such as the FDA (www.fda.gov) or private sources such as industry trade associations (www.bio.orglerlapproveddrugs.asp) provide updated lists of the number of bio-pharmaceuticals that have received market approval, but these lists include a few drugs that may not be bio-pharmaceuticals under some definitions. Furthermore, it is not clear if counts of bio-pharmaceuticals should be limited to new chemical entities (NCEs) or include each therapeutic indication. Some NCEs have multiple indications.

40. There are exceptions. The US FDA requires the efficacy of new antibiotics to be no less $10 \%$ to $20 \%$ below that of existing antibiotics, at a 95\% confidence level (Fletcher, 2002). This requirement ensures timely and effective treatment. 
bio-pharmaceuticals provide an important therapeutic advance, but they are incomplete measures of therapeutic value. For example, they do not compare bio-pharmaceuticals against all existing drugs and the indicators do not measure the degree of therapeutic advance.

The next step is to develop an indicator for the therapeutic benefits of different classes of pharmaceuticals. This type of indicator will be partially based on subjective evaluations of the results of clinical trials. For this reason, the evaluations need to be as unbiased as possible and unaffected by pressure from the pharmaceutical industry, consumer or patient groups, or governments. Unfortunately, many public sources of therapeutic drug evaluations have been closed in the last decade. The FDA for example, stopped classifying drugs into A and B therapeutic classes in the mid-1990s.

One high-quality source consists of the drug evaluations produced by Prescrire, an independent French non-profit organization that is supported by subscriptions to its journal and which receives no government or industry funding. Prescrire assesses the therapeutic value of all new drugs that receive market approval in France, plus approvals for existing drugs to be used for a new indication. The evaluations are based on an expert review of published scientific literature and unpublished data from drug regulators, including the FDA and EMEA, and pharmaceutical firms. Based on the results of the drug evaluation process, Prescrire assigns each drug to one of six therapeutic categories, ranging from a 'major' advance to 'not acceptable' (the drug offers no benefits but has potential or real disadvantages). The measure of therapeutic advance is based, where relevant, on comparisons with existing drugs for the same indication that are already on the market. In addition, a seventh category (judgement reserved) is used when the available data are insufficient for assessing the therapeutic value of the drug. Between 1981 and December 2001, Prescrire assessed 48 biotechnology drugs for 83 indications ${ }^{41}$. The results by indication are given in Table 3 .

Table 3 shows that the therapeutic advance of biotechnology drugs is clearly higher than that for all other drugs, with $32.5 \%$ of biotechnology drugs receiving a rating of 'some' advance or higher, compared to $10.6 \%$ of other drugs. In contrast, only $15.7 \%$ of biotechnology drugs are rated as offering no therapeutic advance over existing drugs on the market, versus almost two-thirds $-66.1 \%$ - of all other drugs. The share of biotechnology drugs offering some or more advance has declined slightly over time from $35 \%$ of 20 drugs introduced between 1981 and 1995, to 31.7\% of 63 drugs introduced between 1996 and 2001, although this is far less than the decline from $14.3 \%$ to $6.9 \%$ for all other drugs. ${ }^{42}$

41. The United States has approved approximately 120 indications for bio-medicines, although these include diagnostics, which are not evaluated by Prescrire, several drugs that are probably not bio-pharmaceuticals, and several drugs that have been approved for use in Europe by the EMEA in the last two years, but which have not yet been evaluated by Prescrire.

42. The results for non-biotechnology drugs shows a marked decline in their therapeutic value, at the same time as R\&D spending by pharmaceutical firms has increased substantially. This raises serious concerns about the productivity of the pharmaceutical sector. Lichtenberg (2001) uses ecological level data to argue that newer drugs result in less mortality than older (presumably off-patent) drugs. This would suggest that newer drugs tend to offer more therapeutic benefits, which contradicts the time series data from Prescrire. However, the methodology used by Lichtenberg is inappropriate to the problem. His findings can also be interpreted to show that newer drugs are more likely than older drugs to be used to treat minor health problems, which would support Prescrire's results and a decline in industry productivity. 
Table 3. Therapeutic advance of biotechnology versus all other drugs receiving market approval in France (1981-2001)

\begin{tabular}{lrrrr}
\hline & \multicolumn{2}{c}{ Biotechnology drugs } & \multicolumn{2}{c}{ All other drugs } \\
& $\mathbf{N}$ & Percentage & $\mathbf{N}$ & Percentage \\
\cline { 2 - 5 } & & $0.0 \%$ & 7 & $0.3 \%$ \\
Major advance & 0 & $10.8 \%$ & 60 & $2.5 \%$ \\
Important advance & 9 & $21.7 \%$ & 185 & $7.8 \%$ \\
Some advance & 18 & $31.3 \%$ & 388 & $16.3 \%$ \\
Minimal advance & 26 & $15.7 \%$ & 1571 & $66.1 \%$ \\
No advance (me too) & 13 & $6.0 \%$ & 55 & $2.3 \%$ \\
Not acceptable & 5 & $14.5 \%$ & 111 & $4.7 \%$ \\
Judgement reserved & 12 & $100 \%$ & 2377 & $100 \%$ \\
Total & 83 & MERIT (2002), based on analyses of Prescrire records for biotechnology drugs. & \\
\hline Sources: & Evaluation of all other drugs: 1981- 1986, Prescrire, 2001; 1987 to 2001, Prescrire, 2002.
\end{tabular}

The Prescrire evaluations could be used as a basis for developing indicators at the national level by adjusting the ratings by the number of new cases of each indication, or the share of all indications (or pharmaceutical prescriptions) that are treated by bio-pharmaceuticals. Both indicators would require some time to calculate (assuming that national records for indications and pharmaceutical use are available) but they would provide a high-quality measure of the benefits of bio-pharmaceuticals. ${ }^{43}$

\subsection{Industrial processing and environmental applications}

Biotechnology has many potential applications in industrial processing, both in the food sector and in pulp and paper, forest products, petroleum refining, textiles, and mining. Most of these biotechnological applications offer cleaner and more environmentally benign solutions to chemical and mechanical processes (OECD, 1998; OECD, 2001c), although their environmental benefits are often a secondary benefit. The main drivers for their development and use are to lower costs by reducing the amount of material and energy inputs per unit of output. Biotechnology can also be used intentionally for its environmental benefits, such as to clean polluted soil, air and water, or to produce renewable energy resources, including ethanol. Jaworski (2002) stresses the potential of a "bio-based" economy in which "eco-efficient bioprocesses and renewable bio-resources make an optimal contribution to sustainable industrial production and sustainable economic growth".

In Canada, the results of the biotechnology surveys show that employment in environmental biotechnology firms has been growing faster than any other type of biotechnology, although from a very small initial base (Arundel and Rose, 1999).

Even though industrial and environmental biotechnology has enormous potential benefits, particularly for environmental sustainability, these two related applications have attracted considerably less attention than health or agricultural uses of biotechnology. This is reflected in considerably lower levels of public and private research funding and very few DBFs active in these fields. A possible exception is Germany, which built up an enormous amount of expertise in this field within DBFs, but German environmental DBFs are suffering from a lack of markets.

43. An additional level of sophistication could be created by adjusting for the expected contribution of bio-pharmaceuticals to reducing mortality and morbidity. 
Part of the problem is that there are only a limited number of current applications of biotechnology for industrial processing (other than the use of enzymes in some processes). This can be illustrated by evaluating the 1998 and 2001 OECD publications on industrial biotechnology. The 1998 publication discusses the potential applications of biotechnology to clean production. The 2001 report provides 21 case studies, which is a major step forward, but the lack of economy-wide indicators is indicative of either limited knowledge of this area, a low rate of adoption, or both. Of note, the Biotechnology Statistics Compendium contains only a few indicators for the industrial and environmental applications of biotechnology. Only Canada, France and New Zealand have collected data, at the firm level, on applications.

The diffusion of industrial biotechnology is hindered by competition with existing processes (Juma and Konde, 2001). This problem is possibly more of a barrier for industrial than agricultural applications (see section 3.2 above) because of the amount of capital invested in existing production equipment.

One feature of industrial and environmental biotechnology is that most of current use is based on "traditional" biotechnology that does not use rDNA technology. Only six of the 21 case studies of industrial applications in the 2001 OECD report using rDNA technology, while all commercial uses of bio-remediation in the United States use wild micro-organisms (Wanabe, 2001). For this reason, indicators of the application of these two technologies must include both traditional and advanced biotechnology.

There are three policy issues that require better indicators for industrial biotechnology. First, industrial and environmental biotechnology must be economically competitive with alternative technologies before they will be widely adopted by firms or widely promoted by Government agencies ${ }^{44}$. Policy support (and private investment) is unlikely to develop without good evidence to demonstrate the economic contribution of industrial biotechnology. But, it is exceedingly difficult to build support for industrial biotechnology on the basis of a limited number of case studies. Given the potential environmental benefits, there is a pressing need to collect relevant indicators on the use of industrial and environmental biotechnology by firms in many different sectors.

The biotechnology surveys in Canada and New Zealand show that industrial biotechnology is not invisible - it does show up ${ }^{45}$. The Canadian survey also included ordinal and nominal questions on the economic benefits of biotechnology. These fairly positive results show that it would be feasible to collect data on the use of industrial and environmental biotechnology in other OECD countries.

The second policy issue concerns the use of scenario analysis as a stop-gap measure for dealing with inadequate indicator data. The main task in a scenario is to identify sectors where industrial biotechnology has potential applications and to estimate the possible impacts of biotechnology on economic output, employment, and environmental measures. An example is the study by Werner and Reiss (2001) for Germany. These estimates are limited to identifiable substitutions of biotechnology for other processes. A second step is to fill out the scenarios with actual data on the application and diffusion of biotechnology in order to estimate future changes over time and to identify potential bottlenecks to the adoption of industrial biotechnology.

44. National representatives from the United Kingdom, the United States, and Germany at the OECD Working Party on Biotechnology meeting in Seville in February 2002 stressed the need for quantifiable, economic data on the effects of industrial biotechnology on employment and production costs.

45. There are few surprises. In Canada, none of the surveyed firms in textiles and leather products reported using biotechnology (Arundel and Rose, 1999), although there are many potential applications in these two sectors. The New Zealand survey, unfortunately, combines industrial processing with a few agricultural applications. The results are therefore less reliable in sectors where both agricultural or industrial processing methods are applicable. 
The third policy issue for indicators is to identify the barriers to research in and the adoption of industrial and environmental biotechnologies. This type of information needs to be obtained from firms that do and do not use industrial biotechnology, either through interviews or surveys. This should be followed by an evaluation of how both the public and private sectors could develop solutions for overcoming these obstacles.

\section{Sourcing new indicators for biotechnology policy}

Table 1 in Section 2 outlines the types of biotechnology indicators that have been collected in at least one OECD country and which are included in the Biotechnology Statistics Compendium. The last column of Table 1 gives the data source. For most indicators, the data are available from government agencies, private consulting firms, or academic organisations. Only a minority of the indicators need to be obtained from surveys by national statistical offices. However, several of these indicators are of great importance to policy. Policy questions on topics such as the strategic importance of biotechnology or the social and economic benefits of biotechnology cannot be fully answered without survey data on applications.

Section 3 identifies the types of indicators that need to be collected in order to address policy issues that apply to all types of biotechnology, while section 4 focuses on policy relevant indicators for each of the three main technology fields: health, agriculture, and industrial processing. Many of these indicators are not included in Table 1 . Therefore, Table 4 summarises these indicators and identifies the types of surveys that would be required to obtain them. There are five main survey types:

1. Standard R\&D surveys.

2. Industry surveys based on a sample of all firms in a sector where biotechnology has potential applications.

3. Surveys of firms that perform Biotechnology R\&D and/or apply or use biotechnology (Biotechnology Survey II).

4. Surveys of firms that perform Biotechnology R\&D (Biotechnology Survey I).

5. Other types of surveys, such as surveys of specific sectors, public research institutes, or households.

Survey types 2, 3, and 4 can be nested. For example, a type 2 survey can include all questions that would otherwise be asked in a type 3 or 4 survey, while a type 3 survey can include questions that would be asked in a type 4 survey.

In many countries, cost or regulatory requirements could prevent National Statistical Offices from implementing several of the types of surveys that would be required to obtain all of the proposed indicators in sections 3 and 4 . Fortunately, many of these indicators can be obtained from alternative sources, while several indicators can be obtained without the use of surveys at all. Table 4 describes alternative non-survey data sources for each indicator, where feasible. 


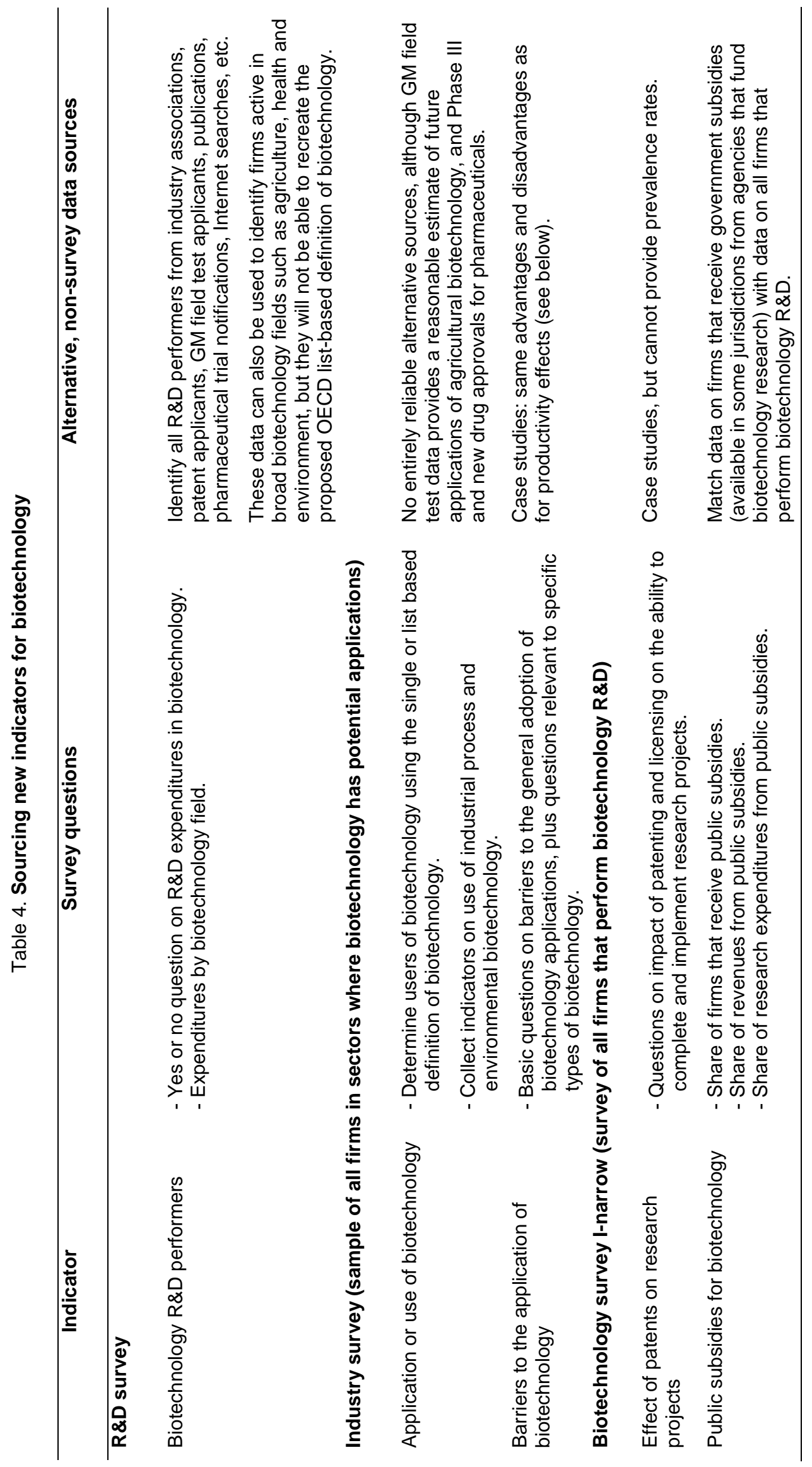




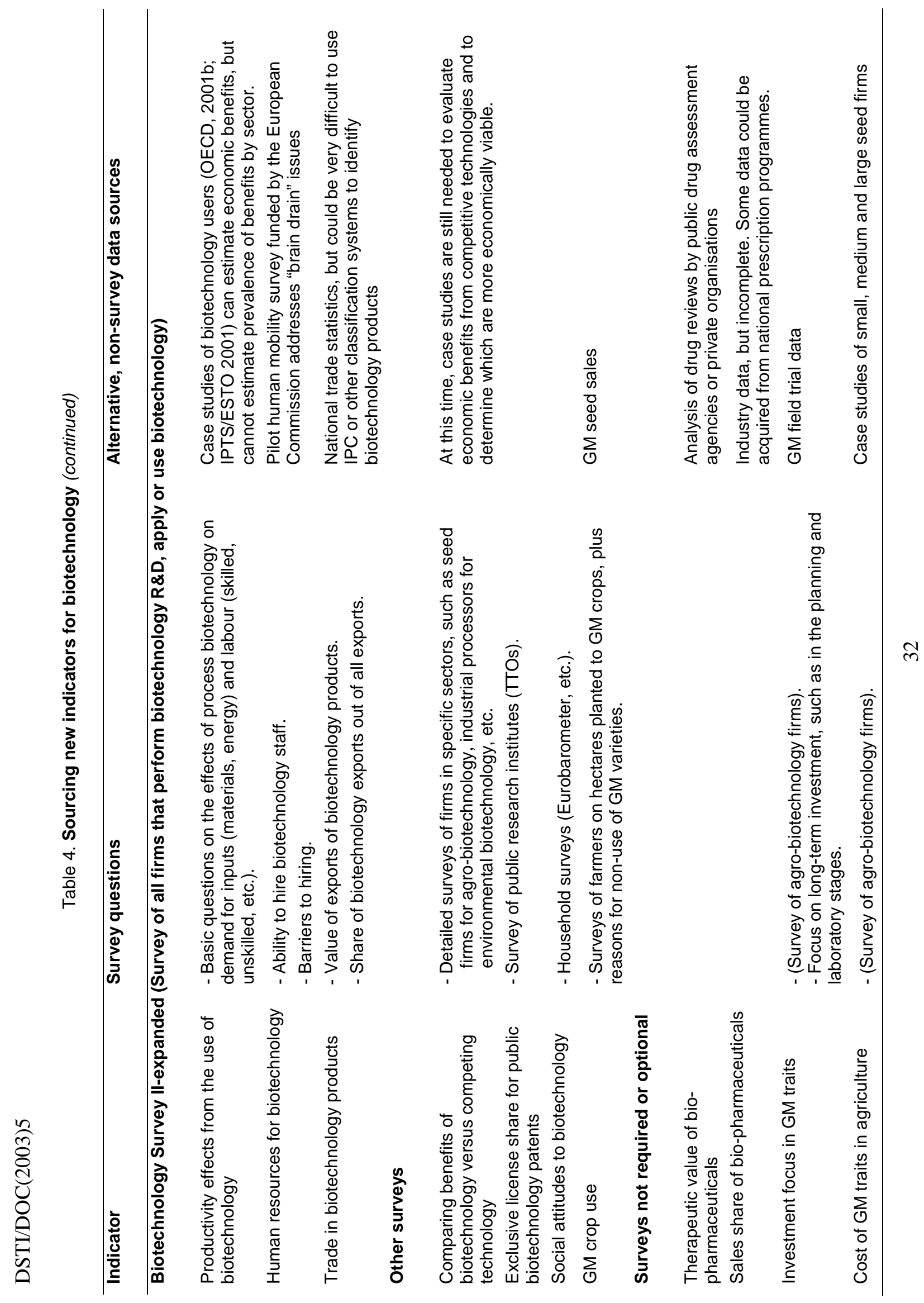


Table 4 does not provide a priority rating for new indicators. It is difficult to do so, since the choice of which indicators to collect will depend on both their value and pragmatic considerations, such as the ability of NSOs to add a question to an existing survey, or implement specialised biotechnology surveys. Nevertheless, three broad priority levels can be constructed. These are based on current needs and the expected changes in the biotechnology sector in the near future, and not on differences in the policy relevance of each priority level.

The first priority is to develop a complete set of relevant indicators for policies to support the development of biotechnology. Many of these indicators are derived from patents, citations, or private sources that do not require surveys. The main requirements are for 1) a complete inventory of firms that perform biotechnology $R \& D$, which can be obtained from either adding a few questions to R\&D surveys or from using multiple alternative sources, 2) data on public and private spending on biotechnology research, 3 ) indicators on the use of public subsidies by private firms, and 4) employment in biotechnology, particularly in large firms where employment data are often unavailable. If possible, all of these indicators should be available for specific biotechnology fields, such as health, agriculture, and industrial processing.

The second priority is to develop indicators of the benefits of biotechnology for health, agriculture, and the environment, as discussed in section 4 above. These indicators can play a role in all of the four policy areas discussed in section 2. On the simplest level, indicators on benefits can be used to be guide policy decisions in R\&D investment, commercialisation, procurement, demonstration projects, etc. Some of the most useful indicators on benefits in the health and agricultural sector do not require surveys. The most difficult area is to develop indicators for industrial processing, with possible productivity and environmental benefits. Most available data are based on case studies, but prevalence data (including for potential applications) are required in order to assess the possible benefits of greater public investment in these technologies, and to identify barriers to their adoption. The latter include both general conditions (such as public opposition) that could hamper the adoption of a wide range of biotechnology processes and products, plus barriers that only apply to specific biotechnology products or processes (such as competitive alternatives or a lack of seed capital for R\&D).

The third priority is based on the assumption that biotechnology should be moving from a development to an applications phase. The main priority is for a set of indicators on biotechnology applications by field. This data can only be obtained from surveys for industrial applications, although analyses of GM field test data can indicate that types of GM seeds that should reach the market in two to five years and data on Phase III trials and new drug approvals can provide similar estimates for pharmaceuticals.

\section{Conclusions}

This report stresses the need to extend indicators for biotechnology from a focus on the creation of biotechnology, to the applications and benefits of biotechnology. Once these indicators are in hand, they can be used to assess the effectiveness of policy support, which in most countries is dominated by S\&T policy to support public and private $R \& D$.

One criticism of this approach is that it proposes using technology forecasting plus information on benefits to determine $\mathrm{R} \& \mathrm{D}$ priorities and to use procurement or other policy instruments to guide private investment towards public goals. The former could be a mistake, since technology forecasting in Europe has generally been unsuccessful (Pavitt, 2000). However, this is probably true when it is impossible for Governments (and society) to form a good idea of what types of technologies would be useful and why. In contrast, many of the potential benefits from biotechnology are obvious because they deal with human problems in health and agriculture. We know that we could use a solution to malaria, and we know that many countries would benefit from wheat varieties that can fix nitrogen. 
In contrast, the market is the best place to leave an assessment of improvements to economic productivity. These issues are best evaluated via economic data and the decisions left to firms. Unless there are unique and irrational barriers to the adoption of biotechnology, there is little justification for policy to encourage firms to adopt biotechnology over alternative technologies. Of course, we need to find out if irrational barriers exist, which is one reason why we include indicators on barriers. If so, demonstration projects, procurement, or other policy instruments could be used to both improve the economic viability of biotechnology and to raise awareness of their potential among firms. The public interest in these types of policies will be greatest for environmental applications and for sustainable industrial production. 


\section{REFERENCES}

Allansdottir A., A. Bonaccorsi and A. Gambardella, et al. (2001), Innovation and Competitiveness in European Biotechnology, Report for DG Enterprise, European Commission, Luxembourg.

Arnold E. and J. Kuusisto (eds) (2002), Government Innovation Support for Commercialisation of Research, New R\&D Performers and R\&D Networks, Tekes, National Technology Agency, Technology Review 121/2002, Helsinki.

Arundel, A. (2002a), GM Field Trials: Relevance to Developing Countries, UNU-INTECH Technology Policy Briefs, 2: 4-5.

Arundel, A. (2002b), “Agro-biotechnology, Innovation and Employment”, Science and Public Policy, Vol. 29, October.

Arundel, A. (2000), "Measuring the Economic Impacts of Biotechnology: From R\&D to Applications", in De La Mothe J. and Niosi J. (Eds), The Economic and Social Dynamics of Biotechnology, Kluwer Academic Publishers, Boston.

Arundel, A. (2001), "Agricultural Biotechnology in the European Union: Alternative Technologies and Economic Outcomes", Technology Analysis and Strategic Management 13:265-279.

Arundel, A. and A. Rose (1998), "Finding the Substance Behind the Smoke: Who is Using Biotechnology?" Nature Biotechnology 16:595-597.

Ashton, G. (2000), “Growing Pains for Biopharmaceuticals”, Nature Biotechnology 19: 307-311.

Autm (2000), AUTM Licensing Survey: FY 1999, Association of University Technology Managers.

Bessen, J. and E. Maskin (2000), "Sequential Innovation, Patents and Imitation", Working Paper, Department of Economics, MIT, January.

Bobrow, M. and S. Thomas (2001), "Patents in a Genetic Age”, Nature, 409: 763-764.

Burke, J.F. and S.M. Thomas (1997), "Agriculture is Biotechnology's Future in Europe”, Nature Biotechnology 15:697.

Buttel, F. (1999), "Agricultural Biotechnology: Its Recent Evolution and Implications for Agrofood Political Economy", Sociological Research Online 4 (3).

Carr, S. (2003), "New Biotechnology, Crop Protection and Sustainable Development", in den Hond, F., P. Groenewegen and N.M. Van Straalen (Eds), Pesticides: Problems, Improvements, Alternatives, Chapter 11. 
Cohen, W., R.R. Nelson and J. Walsh (2001), "Links and Impacts: the Influence of Public Research on Industrial R\&D”, Management Science, forthcoming.

Cowan, R. and E. Harison (2000), "Intellectual Property Rights in a Knowledge-based Economy", MERIT, November.

David P.A. (2001-2003), "Tragedy of the Public Knowledge Commons? Global Science, Intellectual Property and the Digital Technology Boomerang", MERIT Infonomics Research Memorandum Series.

EC (European Commission) (2001), Towards a Strategic Vision of Life Sciences and Biotechnology, Consultation document, Commission of the European Communities, Brussels 4.9.2001 $\operatorname{COM}(2001) 454$ final.

EFPIA (European Federation of Pharmaceutical Industries and Associations) (2001), The Pharmaceutical Industry in Figures - 2001 Edition, EFPIA, Brussels.

Einsiedel, E. (2000), "Cloning and its Discontents - a Canadian Perspective", Nature Biotechnology 18:943-945.

Ernst \& Young (1998), New Directions 98, Ernst and Young, San Francisco.

Ernst \& Young (1999), European Life Sciences 99, Ernst and Young International, Stuttgart.

Ernst \& Young (1999b), Biotech 99: Bridging the Gap, Ernst and Young, San Francisco.

Ernst \& Young (2001), Focus on Fundamentals: The Biotechnology Report (15 th Annual Review), Ernst \& Young, San Francisco, October.

Ernst \& Young (2002), Beyond Borders: The Global Biotechnology Report 2002, Ernst and Young, Mannheim, June.

EuropaBio (2001), White Biotechnology: Cleaner Processes for a Cleaner Environment, EuropaBio, Brussels.

EZ (Ministry of Economic Affairs) (2002), "Patenting and Licensing by Dutch Public Research Organisations", Economische Zaken, Den Haag, April.

Fernandez-Cornejo J. and W.D. McBride (2000), "Genetically Engineered Crops for Pest Management in US Agriculture: Farm-level Effects”, Economic Research Service, US Dept Agriculture, Report No. 786, Washington DC, April.

Fisher, W. (2001), "Intellectual Property and Innovation, Theoretical, Empirical and Historical Perspectives", Beleidstudies Technologie Economie 37:47-72.

Fletcher, L. (2002), “Cubist Highlights FDA's Antibiotic Resistance”, Nature Biotechnology 20:206-207, 2002.

Freeman C. and C. Perez (1998), "Structural Crises of Adjustment, Business Cycles and Investment Behaviour", in G. Dosi et al (Eds), Technical Change and Economic Theory, Pinter, London. 
Fulton, F. and K. Giannakas (2001), "Agricultural Biotechnology and Industry Structure”, AgBioForum 4:13-151.

Gallini, N. and S. Scotchmer (2001), "Intellectual Property: When is it the Best Incentive System?" Mimeo, U. of Toronto, May 6.

Gao (1999), "Technology Transfer: Number and Characteristics of Inventions Licensed by Six Federal Agencies", GAO, Washington DC, June.

Gaskell, G., N. Allum and M. Bauer, et al. (2000), "Biotechnology and the European Public", Nature Biotechnology 18:935-938.

Heller, M. and R. Eisenberg (1998), "Can Patents Deter Innovation? The Anticommons in Biomedical Research”, Science 280:698-701.

IPTS/ESTO (2001), "The Assessment of Future Environmental and Economic Impacts of Process-Integrated Biocatalysts”, European Commission, DG JRC, IPTS, ESTO, Seville, December.

Jaffe, A.B. (1999), "The US Patent System in Transition: Policy Innovation and the Innovation Process", NBER Working Paper 7280, August.

Jaworski, J. (2002), "The Bio-Based Economy: Pathway to a Sustainable Future", presentation to the workshop Advanced Industrial Production with Process Integrated Biotechnologies, Institute for Prospective Technology Studies (IPTS), Seville, February 21-22.

Juma, C. and V. Konde (2001), "Industrial and Environmental Applications of Biotechnology", paper for the UN Conference on Trade and Development, Geneva, October 26.

Kingston, W. (2001), “Innovation Needs Patent Reform”, Research Policy 30:403-423.

Laestadius, S. (1998), "The Relevance of Science and Technology Indicators: the Case of Pulp and Paper", Research Policy 27:385-395.

Laget, P. and M. Cantley (2001), "European Responses to Biotechnology: Research, Regulation and Dialogue", Issues in Science and Technology Online, Summer.

Levidow, L. and C. Marris (2001), "Science and Governance in Europe: Lessons from the Case of Agricultural Biotechnology", Science and Public Policy 28:345-360.

Lichtenberg, F. (2001), "The Benefits and Costs of Newer Drugs: Evidence from the 1996 Medical Expenditures Panel Survey", NBER Working Paper W8147.

Mazzoleni, R. and R. Nelson (1998), "The Benefits and Costs of Strong Patent Protection: A Contribution to the Current Debate", Research Policy 27:273-284.

Menrad, K., M. Menrad, D. Vorgrimmler, K. Lhereux, M. Libeau-Dulos and E. Cerezo (2002), Anticipating Commercial Introduction of GMOs in the EU, IPTS, Seville, September.

Merit (2002), Indicators for a Bio-based Economy: Tracing Applications and Potential Benefits, available on request from A.Arundel@ merit.unimaas.nl, February.

Mitchell P. (2002), “Cash-strapped Firms Face Stormy Time”, Nature Biotechnology 20:5-6. 
Nelson G. (2001), Genetically Modified Organisms in Agriculture: Economics and Politics, Academic Press.

Nesta L. and V. Mangematin (2002), "Industry Life Cycle, Knowledge Generation and Technological Networks", presentation to International Research Workshop on Alliances, Networks, and Partnerships in the Innovation Process, Ottawa, Canada, February 28 - March 1.

Nuffield Council on Bioethics (2002), The Ethics of Patenting DNA, Nuffield Council, London, July.

OECD (1998), Biotechnology for Clean Industrial Products and Processes, OECD, Paris.

OECD (2001a), "Innovation and Strategic Use of IPRs", issues paper, DSTI/STP/TIP(2001)4, OECD, Paris.

OECD (2001b), “The Application of Biotechnology to Industrial Sustainability”, OECD, Paris.

OECD (2001c), "A Statistical Framework for Biotechnology Statistics”, DSTI/EAS/STP/NESTI(2001)39, OECD, Paris.

OECD (2002), "IPRs and Innovation in PROs", Working Group on Innovation and Technology Policy, DSTI/STP(2002)42, OECD, Paris.

Pavitt, K. (2000), "Academic Research in Europe", SPRU Electronic Working Papers Series no. 43, University of Sussex.

P.E.W. (2001), "Initiative on Food and Biotechnology", Harvest on the Horizon: Future Uses of Agricultural Biotechnology, PEW, September.

Prescrire (2001), “L’année 2000 des médicaments”, La Revue Prescrire 21:57-64.

Prescrire (2002), “L’année 2001 du médicaments”, La Revue Prescrire 22:54-62.

Priest, S.H. (2000), “US Public Opinion Divided Over Biotechnology?” Nature Biotechnology 18:939-942.

Rose, A. (2002), "Biotechnology Use and Development: Towards a Model Survey", draft mimeo, SIEID Division, Statistics Canada, Ottawa, January.

Ruttan, V.W. (1999), “Biotechnology and Agriculture: A Skeptical Perspective”, AgBioForum 2:54-60.

Sechler, B. (2001), "Food, Agriculture Miss Out on Biotech Investment Boom”, Dow Jones Newswires, Monday, August 27.

Senker, J. and P. Van Zwanenberg (2000), "European Biotechnology Innovation System: EC Policy Overview", DG Research, European Commission, TSER Contract no. SOEI-CT98-1117, September.

Siune, K. (2002), "A Module on Social Issues as concerns Biotechnology", The Danish Institute for Studies in Research and Research Policy, April.

Statistics New Zealand (2001), "Modern Biotechnology Activity in New Zealand", Statistics New Zealand, Wellington, April. 
Tait, J., J. Chataway and D. Wield (2001), "Policy Influences on Technology for Agriculture: Chemicals, Biotechnology and Seeds", Report to DG Research of the European Commission, January.

US Congressional Report (2001), "Seeds of Opportunity”, US Congress, House Subcommittee on Basic Research, April 13.

Van Beuzekom, B. (2001), "Biotechnology Statistics in OECD Member Countries: Compendium of Existing National Statistics”, STI Working Papers 2001/6, OECD, Paris, September.

Verspagen, B. (1999), “The Economic Importance of Patents”, MERIT research memorandum 99-017.

Walsh, J.P., A. Arora and W. Cohen (2001), "The Patenting of Research Tools and Biomedical Innovation", background paper to the National Academies of Science meeting on Intellectual Property Rights, October.

Watanabe, M.E. (2001), “Can Bioremediation Bounce Back?” Nature Biotechnology 19:1111-1115.

Werner, S. and T. Reiss (2001), "The Direct and Indirect Impacts of New Technologies on Employment: the Example of the German Biotechnology Sector", Science and Public Policy, 28, pp.1-10.

Williamson, A.R. "Gene Patents: Socially Acceptable Monopolies or an Unnecessary Hindrance to Research?" Trends in Genetics, forthcoming. 